Portland State University

PDXScholar

6-6-1993

\title{
A Comparison of Ambient and Hearing Aid Output Noise Levels in Industrial and Non-industrial Settings
}

Jody Lynn O'Connor

Portland State University

Follow this and additional works at: https://pdxscholar.library.pdx.edu/open_access_etds

Part of the Communication Sciences and Disorders Commons

Let us know how access to this document benefits you.

Recommended Citation

O'Connor, Jody Lynn, "A Comparison of Ambient and Hearing Aid Output Noise Levels in Industrial and Non-industrial Settings" (1993). Dissertations and Theses. Paper 5147.

https://doi.org/10.15760/etd.7023

This Thesis is brought to you for free and open access. It has been accepted for inclusion in Dissertations and Theses by an authorized administrator of PDXScholar. Please contact us if we can make this document more accessible: pdxscholar@pdx.edu. 


\section{THESIS APPROVAL}

The abstract and thesis of Jody Lynn O'Connor for the Master of Science in Speech Communication: Speech and Hearing Science were presented June 6, 1993, and accepted by the thesis committee and the department.

COMMITTEE APPROVALS:
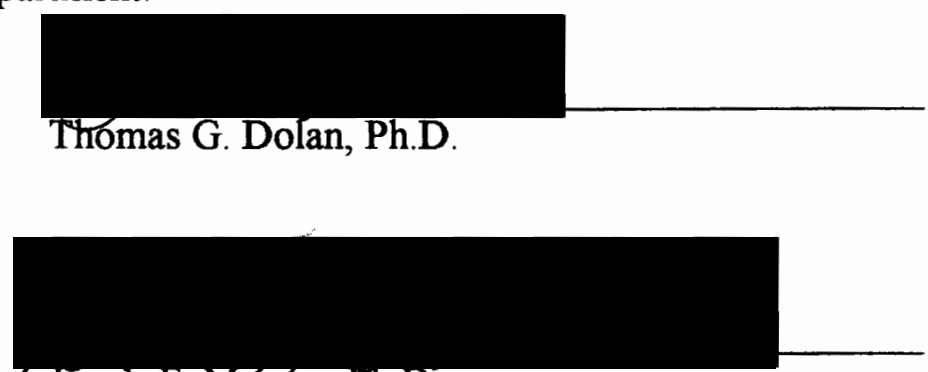

James F. Mgyrer, Ph.D.

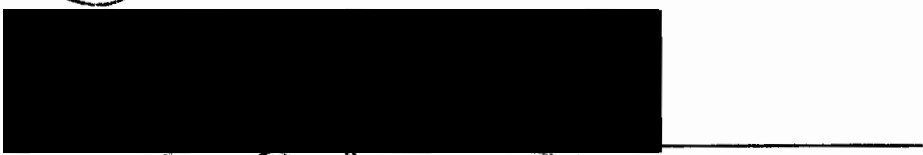

Douglas C. Martin, Ph.D.

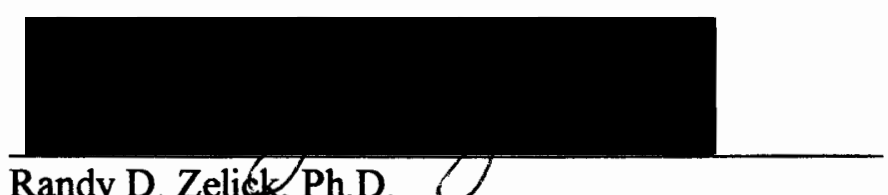

Representative of the Office of Graduate Studies

DEPARTMENT APPROVAL:

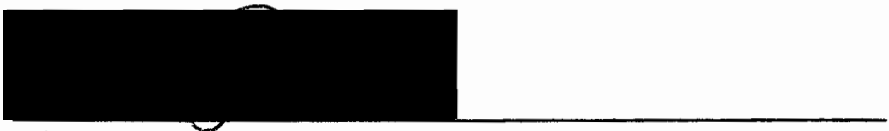

Rhea Paul, Ph.D., Chair

Department of Speech Communication

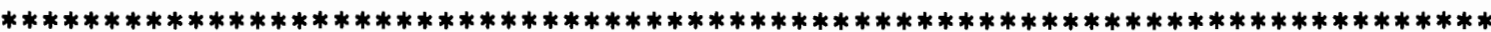

ACCEPTED FOR PORTLAND STATE UNIVERSITY BY THE LIBRARY

by

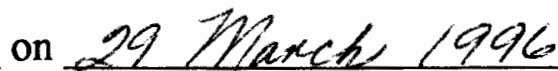


AN ABSTRACT OF THE THESIS OF Jody Lynn O'Connor for the Master of Science in Speech Communication: Speech and Hearing Science presented June 6, 1993.

Title: A Comparison of Ambient and Hearing Aid Output Noise Levels in Industrial and Non-Industrial Settings.

Federal regulations specify that an employee working for eight hours cannot legally be exposed to noise which has a time-weighted average greater than 90 decibels on the A scale. The industrial workforce is comprised of not only people with normal hearing acuity, but of individuals who suffer from hearing loss. While current noise regulation standards are deemed appropriate for those with normal hearing, it is difficult to apply these standards to persons wearing hearing aids on the job. The ambient, or unamplified, noise levels that fall below the maximum permitted by OSHA standards may very well be amplified to levels greater than $90 \mathrm{dBA}$, by the hearing aid. If this were the case, the company employing the hearing aid user would technically be in violation of the OSHA regulations.

This study addressed the question of what noise exposure might be expected for hearing aid users on the job in different situations, as well as in non-vocational settings. The research involved two methods, conducted to determine the noise levels created by hearing aids with different amounts of gain and to determine whether the amplified noise levels exceed those requiring intervention under current regulations. For both methods, ambient and amplified noise levels for each condition were gathered in 
specified increments, and were compared with regard to current regulatory standards.

The resultant data revealed that when ambient noise levels average between 80 and $84 \mathrm{dBA}$, amplification provided by even a mild gain hearing aid caused the eight hour time-weighted averages (TWA's) to increase to levels above the 90 dBA maximum permissible levels as delineated by OSHA. Moderate and high gain aids further increased these levels.

The results of this study suggest that the hearing aid users in industrial and perhaps non-industrial settings may very well be exposed to intensity levels which exceed OSHA maximums, even when ambient levels do not. The extent to which these are exceeded are based on the gain and output of the hearing aid in use. 
A COMPARISON OF AMBIENT AND HEARING AID OUTPUT NOISE LEVELS IN INDUSTRIAL AND NON-INDUSTRIAL SETTINGS

by

JODY LYNN O'CONNOR

A thesis submitted in partial fulfillment of the requirements for the degree of

MASTER OF SCIENCE

in

SPEECH COMMUNICATION:

SPEECH AND HEARING SCIENCE

Portland State University

1996 


\section{TABLE OF CONTENTS}

PAGE

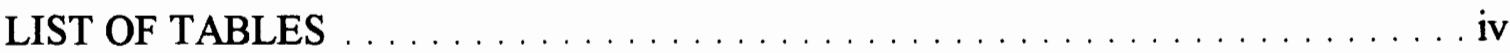

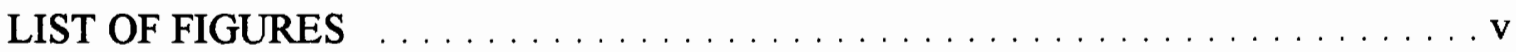

\section{CHAPTER}

I INTRODUCTION $\ldots \ldots \ldots \ldots \ldots \ldots \ldots \ldots \ldots \ldots$

II REVIEW OF THE LITERATURE $\ldots \ldots \ldots \ldots \ldots \ldots$

Types of Hearing Loss $\ldots \ldots \ldots \ldots \ldots \ldots \ldots$

Hearing Loss Attributable to Noise Exposure $\ldots \ldots \ldots \ldots \ldots 7$

Physiological Effects of Noise Exposure. . . . . . . . . . 10

Regulation of Noise Exposure. . . . . . . . . . . . . . 14

Damage Risk Criteria. . . . . . . . . . . . . . . . . . 18

Current Criteria and Guidelines. . . . . . . . . . . . . . 19

Hearing Loss Associated With Hearing Aid Use. . . . . . . . 20

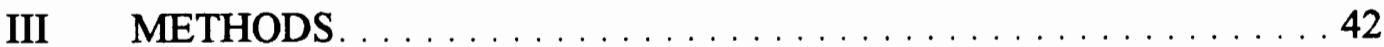

Method One ............................ 42

Method Two. .......................47

Instrumentation and Procedures

Industrial Sound Level Measurements

Non-Industrial "Everyday" Sound Level Measurements 
PAGE

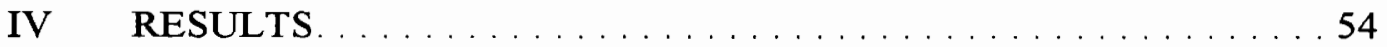

$\mathrm{V} \quad \operatorname{DISCUSSION} \ldots \ldots \ldots \ldots \ldots \ldots \ldots \ldots \ldots$

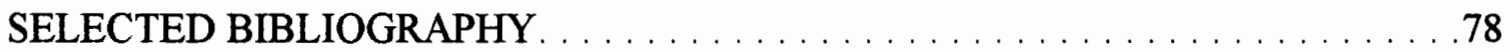

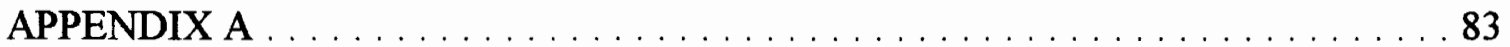




\section{LIST OF TABLES}

TABLE

PAGE

I Hearing aid type, gain and output 46 


\section{LIST OF FIGURES}

FIGURE

PAGE

1. Aerial View of Sulzer-Bingham Noise Recording Sites

2. Aerial View of Acoustic Chamber Noise Analysis Site.

3. Instrumentation Layout for Comparison of Coupler

Differences, Including Bruel \& Kjaer Sound

Level Meter and Larson Davis 700 Dosimeter

4. Coupler Output Level in Decibels Sound Pressure Level

by Frequency, $\mathrm{kHz}$.

5. Example Output Levels by Dosimeters When Measuring

Ambient Noise and When Coupled to Hearing Aid.

6. Comparison of Hearing Aid Equivalent Continuous Noise

Level (Leq) in dBA as a Function of Time, as

Measured in $\mathrm{Cab}$ of Locomotive

7. Projected Eight Hour Time-Weighted Averages (TWAs)

in $\mathrm{ABA}$, Calculated by Integrating Sound Level

Meter, Using Locomotive Noise Recordings

8. Equivalent Continuous Noise Level (Leq) in $\mathrm{dBA}$ as a

Function of Time, Turret Lathe Recording

9. Projected Eight Hour Time-Weighted Averages (TWAs)

in $\mathrm{dBA}$, Calculated by Integrating Sound Level

Meter, Turret Lathe Recording

10. Equivalent Continuous Noise Level (Leq) in $\mathrm{dBA}$ as a

Function of Time, Manufacturing Plant Setting,

Starkey CE Hearing Aid 
11. Equivalent Continuous Noise Level (Leq) in dBA as a Function of Time, Manufacturing Plant Setting, Bausch \& Lomb R6 Hearing Aid

12. Equivalent Continuous Noise Level (Leq) in $\mathrm{dBA}$ as a

Function of Time, Manufacturing Plant Setting,

Widex A18 $+\mathrm{H}$ Hearing Aid

13. Eight Hour Time-Weighted Averages (TWAs) in $\mathrm{dBA}$ as Calculated by Dosimeters Coupled with Hearing Aids, Manufacturing Plant Setting 66

14. Equivalent Continuous Noise Level (Leq) in dBA as a Function of Time, Non-Industrial "Every-day" Setting, Bausch \& Lomb R6 Hearing Aid, Home, Driving, Shopping, Outdoor Barbecue 68

15. Equivalent Continuous Noise Level (Leq) in $\mathrm{dBA}$ as a Function of Time, Non-Industrial "Every-day" Setting, Bausch \& Lomb R6 Hearing Aid, Home, Restaurant, Nightclub

16. Equivalent Continuous Noise Level (Leq) in $\mathrm{ABA}$ as a Function of Time, Non-Industrial "Every-day" Setting, Widex A18+H Hearing Aid, Christmas Day . .

17. Eight Hour Time-Weighted Averages (TWAs) in dBA as Calculated by Dosimeters Coupled with Hearing Aids, Non-Industrial "Every-day Settings. 


\section{CHAPTER I}

\section{INTRODUCTION}

Hearing loss caused by exposure to high levels of noise has been documented in studies of both animals and humans (Bohne, 1976; Botsford, 1967; Burns, 1973; Mills, 1973; Sataloff, Menduke and Hughes, 1962; Suter, 1988; Tempest, 1985; Ward, 1969, 1984). Prior to the industrial revolution, reports of such hearing loss were primarily confined to cases within the military or in careers such as blacksmithing (Suter, 1986). With the arrival of industrialization came increased reports of hearing loss. One example noted often in the literature is "boiler-maker's ear", referring to the high-frequency loss commonly attributed to those working in steel factories where steel plates were hammered and riveted during construction of boilers used in coal-fired steam engines (Burns, 1973). With industrialization and manufacturing came noise levels which have put the auditory status of its employees at risk for hearing loss.

Federal regulations presently outline the intensity levels to which employees can be exposed over specified periods of time. Initially, such regulation was referred to as the 1969 Walsh-Healey Public Contracts Act, and stipulated that the noise levels where people were employed must be "reasonably controlled" (Melnick, 1985; Suter, 1988). The actual intensity levels and permissible periods of exposure delineated by present law were decided upon on the basis of several years of research and compromise (Lipscomb, 
1988; Melnick, 1985; Suter, 1988).

Currently, federal standards are governed by the Occupational Safety and Health Act (OSHA) of 1970 (Suter, 1988). It requires that administrative and/or engineering controls be implemented to effectively limit noise levels in industry to specified levels, based on the time of exposure. For example, an employee working for eight hours cannot legally be exposed to noise levels which average greater than 90 decibels. While such levels are closely monitored to assure that they are within legal limits, and that hearing protection is provided when deemed necessary, there is yet another issue which has not been addressed.

The industrial workforce is made up not only of people with normal hearing acuity, but of individuals who suffer from hearing loss. As of 1989, a reported 20,246,000 people, equivalent to 83.1 per 1000 in the United States had a hearing loss. Of these, 175.5 per 1000 were between the ages of 18 and 64 years, 98.5 per 1000 were men, and 68.7 were women (U.S. Department of Commerce, 1992). In the same year, according to the U.S. Hearing Aid Sales Summary, over 1.5 million hearing aids were sold, an increase of 1.2 percent over 1988 (Kirkwood, 1990). In addition, a review of previous summaries shows that the number of aids sold in the U.S. has increased steadily throughout the last decade (Mahon, 1984, 1985, 1987, 1989).

There is a growing problem due to the number of hearing aids being worn on the job. The reasons that people wear these aids on the job are at times matters of life and death. They must be able to hear specific sounds in their work environment, which may include hints of instrumentation malfunction critical to the safety of themselves and others. 
Considering these facts, it is necessary to examine the potential for individuals working in loud settings to be exposed to noise levels beyond that determined to be legally within the existing guidelines. To clarify, the ambient noise levels that fall below the maximum permitted by OSHA standards may very well be raised to levels greater than $90 \mathrm{dBA}$, due to the hearing aid's amplification. If this is the case, the company employing the hearing aid wearer would technically be in violation of the OSHA regulations.

Previous research has focused on the potential for exacerbation of an existing hearing loss due to overamplification (Bellefleur \& Van Dyke, 1968; Harford \& Markle, 1955; Holmgren, 1939; Humes, 1978; Jerger \& Lewis, 1975; Kinney, 1961; Macrae, 1968, 1991; Macrae \& Ferrant, 1965; Markides, 1976; Naunton, 1957; Reilly, Owens, Uken, McClatchie \& Clarke, 1981; Rintelmann \& Bess, 1977; Roberts, 1970; Ross \& Lerman, 1967; Ross \& Truex, 1965; Sataloff, 1966). However, these studies have addressed the issue with regard to "normal", or "everyday" listening situations. The problem of amplified industrial noise has not been addressed in the literature.

Humes \& Bess (1981) refer to results of an investigation of the potential for auditory decrement due to amplification by hearing aids. A subject with normal hearing acuity wore an aid set to three output levels supplying gains of $40.5,46.2$, and $54.3 \mathrm{~dB}$. While seated one meter from a loudspeaker, he was presented with $70 \mathrm{dBA}$ (measured at ear level) of four-talker speech babble for 57 minutes, and temporary threshold shift was measured. However, the presentation of noise at a constant level is not an adequate representation of sound in the environment. Noise fluctuates, its intensity increasing and decreasing over time, an element not accounted for in this study. In addition, 
measurements of noise in this study were made with a sound level meter, which does not integrate sound levels over time. As stated by Lipscomb (1988), data acquired to determine a person's actual sound exposure is best done with a dosimeter.

Macrae (1991) also reported threshold shifts due to hearing aid overamplification. He measured office noise with a sound level meter while holding the microphone "close to one of his ears". One-third octave band levels of this noise were measured and integrated over ten minutes for each band, which was then considered the "typical input sound". An estimation of one-third octave band levels of certain hearing aids was attained by adding 2-cc coupler gain to the "typical input". Based on this, aided levels generated by hearing aids worn by each of eight children were estimated by adding the appropriate 2-cc coupler-to-real-ear correction to the 2-cc coupler levels, as suggested by Skinner (1988). Again, sound levels were not integrated over time, so fluctuations over long periods were not accounted for.

This study addressed the question of what noise exposures might be expected for hearing aid users on the job in different situations, including the issue of amplified industrial noise. The purpose was also to ascertain the noise levels created by hearing aids providing different amounts of gain, and whether or not the amplified sound pressure levels give rise to time-weighted averages (TWA's) exceeding those requiring intervention under current OSHA regulations. The ambient noise levels, as well as the output of several types of hearing aids were both measured in industrial settings and in the lab were integrated by means of an integrating sound level meter or dosimeter. In addition, sound measurements of "everyday" environments, such as the classroom, home and shopping, 
were made. 


\section{CHAPTER II}

\section{REVIEW OF THE LITERATURE}

Over the years, a number of authors have detailed the effects of auditory overstimulation caused by excessive noise levels (Dennis \& Neely, 1991; Gulick, Gescheider \& Frisina, 1989; Newby \& Popelka, 1985; Tempest, 1985; Ward, 1969, 1984; Yost \& Nielsen, 1985). Such exposure can cause temporary or permanent loss of hearing Types of Hearing Loss

Temporary loss can occur if an individual is exposed to high levels of continuous noise for a period of several hours, or to very brief exposures to high intensity shortincrement noise, such as a gunshot. This can lead to an upward "shift" of a person's threshold for sound. That is, the intensity level at which they are able to first detect a sound of a given frequency or range of frequencies is increased due to the noise. The amount of threshold shift is determined primarily by the frequency spectrum, intensity and duration of the noise. The actual intensity required to cause a temporary threshold shift of 5 decibels $(\mathrm{dB})$ or more varies, but is reported to be in the area of 73 to $80 \mathrm{~dB}$ sound pressure level (SPL) (Gulick et al., 1989). Following cessation of the noise, the hearing level can return to normal, or to the level that it was prior to the exposure.

Permanent threshold shift (hearing loss) is much more detrimental, and typically occurs due to repeated exposure to intense SPL's over a period of years. Two primary 
categories of permanent noise-induced hearing loss are referred to in the literature, namely "sociocusis" (Ward, 1969) and "occupational", also known as "industrial noise-induced permanent threshold shift" (Burns, 1973). Briefly, sociocusis refers to permanent loss attributed to unhealthful doses of auditory stimulation by sources other than those in the individual's workplace. Examples of such sources include lawn mowers, guns, power tools, outboard motors and stereo equipment. Occupation loss, on the other hand, refers to a permanent loss of hearing acuity which can be attributed specifically to exposure to hazardous levels of noise in the workplace (Fox, 1957).

\section{Hearing Loss Attributable to Noise Exposure}

Literature documenting hearing loss said to be attributable to noise exposure includes cases dating back as far as the 1700 's, when a military admiral reportedly was nearly deafened by the hardware being fired from the ship (Burns, 1973). While this loss was reported to have been temporary, Burns also cites a case in which an officer is said to have been permanently deafened by artillery fire.

With the advent of industrialization, the importance of monitoring sound levels and the hearing of those exposed became apparent as reports of hearing loss in workers increased. The prevalence of hearing loss among those employed in loud settings has been assessed throughout the years.

The results of some of these studies were fittingly reviewed and interpreted in a 1967 report by Botsford. Threshold data was analyzed to determine the prevalence of hearing impairment based on age and years of exposure to occupational noise. When graphed, data points revealed that "...each decibel of occupational noise above $84 \mathrm{dBA}$ 
(SPL) increases the prevalence of impaired hearing by approximately the same amount as would one year of aging" (p. 81). While it remained somewhat questionable whether this determination was actually an over- or underestimation of the "aging" effects that noise can have on the auditory system, it still supported the notion that certain levels of noise exposure are indeed detrimental to the employee's hearing.

Determination of the exposure level at which auditory change begins to occur has been the subject of study for many years. Though still somewhat controversial, some basic distinctions have been made and reported in the literature. The National Institute for Occupational Safety and Health (NIOSH) (cited in Suter, 1988) conducted research between 1968 and 1972. They studied the hearing loss in 792 industrial plant employees exposed to daily levels of 85,90 and $95 \mathrm{dBA}$, and compared their thresholds to those of 380 controls exposed to levels below $80 \mathrm{dBA}$. Data were presented as a function of intensity level and duration of exposure. Results revealed that those exposed to intensity levels of $85 \mathrm{dBA}$ or greater had poorer hearing sensitivity at all frequencies tested than did those exposed to $80 \mathrm{dBA}$ or less, with the greatest shifts being in the higher frequencies (4 $\mathrm{kHz}$ and above).

Similar research by Berger, Royster \& Thomas (1978) included investigation of noise-induced threshold shift caused by up to 10 years' exposure to $89 \mathrm{dBA}$ in an industrial plant. Though some questionable methods and combination of test subjects occurred, the end result was that there was a definite shift in hearing thresholds at $4 \mathrm{kHz}$ when exposed to daily levels of $89 \mathrm{dBA}$, results which the authors state were consistent with those of other researchers. This study was not well-controlled, however. The test 
subjects included people with military history, and exposure to non-industrial noise such as farming machinery, hunting, and power tools.

Merely looking at intensity levels to which employees are exposed does not tell the entire story. The length of exposure is also an issue that has to be weighed into the calculation. Burns \& Robinson (1970) report of a study of 759 English factory workers exposed to average intensities ranging from approximately 75 to $120 \mathrm{dBA}$, for periods ranging from 1 to 50 years. A comparison of results revealed that the amount of hearing loss incurred due to a relatively short-term exposure to high levels of noise was very similar to that incurred when exposed to lower levels of noise for longer periods. Based on this and other data obtained, the authors reported that calculation of intensity-duration relationships can be done, and predictions of noise-induced permanent threshold shifts can be made.

Yates, Ramsey \& Holland (1976) compared the damage risk of 85 versus $90 \mathrm{dBA}$ of white noise for one-half days and that of full days of exposure by analyzing temporary threshold shift in the subjects exposed. Using statistical analysis (Duncan multiple range test), their information revealed two facts. First, the potential damage risk (the possibility of a person suffering some noise-induced hearing loss) is definitively greater for exposures of $90 \mathrm{dBA}$ than those of $85 \mathrm{dBA}$. Also, the damage risk was shown to be consistent with present guidelines as stated by the Occupational Safety \& Health Association (OSHA): That the effects of $90 \mathrm{dBA}$ over four hours is equal to that of $85 \mathrm{dBA}$ over eight hours, and vice versa. Details of these and other elements of the OSHA guidelines will be reported later in this writing. 


\section{Physiological Effects of Noise Exposure}

More recent research has addressed the topic of hearing loss due to high levels of noise, based on studies of both animals and humans (Bohne, 1976; Botsford, 1967; Burns, 1973; Gulick et al., 1989; Mills, 1973; Sataloff et al., 1962; Suter, 1988; Tempest, 1985; Ward, 1969, 1984). Acoustic overstimulation has been found to cause varying degrees of cochlear damage. Depending upon the intensity and duration of the noise exposure, physiological changes can result in temporary and/or permanent morphological mutation. Animal research makes up the majority of that performed in an effort to establish the physiological effects of noise. While this evidence is useful to a certain degree, it is pointed out that there seems to be some disagreement among authors as to the validity of applying the effects on the animal's auditory system to that of the human (Newby \& Popelka, 1985).

Studies on animals do not necessarily provide the best estimation of the potential effects on humans, given the same noise exposures. Yost \& Nielsen (1985) state that the pattern of cochlear hair cell damage and the loss incurred can vary a good deal from one individual to another. In addition, they note that certain animal species are more or less prone than others to acoustic damage from noise exposure. However, in an attempt to understand the morphological changes which occur due to acoustic overstimulation, the results of animal studies will be presented.

Exposure to short-duration intense noise can result in circulatory changes in the cochlea, while long-term exposure to even moderate noise levels may result in a decrease in oxygen supply and swelling of the hair cells (Silman \& Silverman, 1991). Stereocilia 
may become "floppy", or bend over, and the swollen hair cells may fuse together in the outer rows when exposed to even low or moderate levels of intensity (Gulick et al., 1989). However, high levels may actually cause separation of the Organ of Corti from the basilar membrane (Saunders, Yale \& Szymko, 1991; Ward, 1986; Yost \& Nielsen, 1985). When the hair cells swell and the cilia becomes detached from the tectorial membrane, there is a reduction of hair cell sensitivity to motion within the cochlear fluids. Due to these subtle changes, it takes more acoustic energy input to initiate neural activity than it did prior to the noise exposure.

The latest findings in this area of research are included in a well-written update by Saunders et al. (1991). There are transduction channels at the tips, or along the shafts of the hair cell stereocilia, one to four channels per hair. Movement of the cilia, due to acoustic stimulation and flow of lymphatic fluid within the cochlea opens these channels, permitting potassium ions to enter the cell, resulting in depolarization of the cell. When the depolarization reaches the base of the cell, a neurotransmitter is released, and the signal continues to the auditory nerve.

Recent research by Cody \& Russell (cited in Saunders et al., 1991) has shown that outer hair cell motility is slowed when the cell is exposed to a medium comprised of a high level of potassium. When exposed to intense overstimulation, the flow of potassium into the outer hair cell is assumed to be greater than the outflow at the base, causing an accumulation of intracellular potassium. The resulting depolarization leads to a contraction of the cell. Such "shortening" changes the mechanics at the basilar membrane, and can alter stimulation of the inner hair cell. It is thought that such outer hair cell 
depolarization may continue, even after the exposure to the noise which started such action, and that the activity of the inner hair cell may be ultimately affected. If so, afferent conduction of the acoustic signal may be influenced because approximately $95 \%$ of the afferent nerve fibers innervate the inner hair cells (Yost \& Nielsen, 1985).

Research by Canlon (cited in Saunders et al., 1991) suggested that overstimulation may change not only the morphology and physiology of hair cell cilia. In addition, cilia motility may be affected, and structural damage of the tectorial membrane may occur. A $1000 \mathrm{~Hz}$ pure tone stimulus presented at $105 \mathrm{~dB}$ SPL resulted in a "waviness", or change in the tectorial membrane thickness over the entire length of the cochlea.

Saunders et al. (1991) also reported a study in which guinea pigs were exposed to only two minutes of $3000 \mathrm{~Hz}$ tones $125 \mathrm{~dB} \mathrm{SPL}$, and suffered displacement, fusion and complete fracture of stereocilia on the first row of outer hair cells, while only a sparse number of inner hair cells were injured. However, as duration of exposure increased, damage spread to all three rows of outer hair cells and inner hair cells as well. In addition, it was stated that with regard to auditory nerve function, physiological damage to inner hair cell stereocilia had a greater effect on auditory function than did similar damage to the outer hair cell's stereocilia.

Yet another area of concern is the effect of overstimulation on the tip links of the stereocilia. The tip links act as cross-links between stereocilia, and are assumed to have a role in the transduction process. These structures have been examined in guinea pigs, lizards and birds, following exposure to intense sounds. Pickles et al. (cited in Saunders et al., 1991) found that following exposure to a $10 \mathrm{kHz}$ pure tone of $117 \mathrm{~dB}$ SPL for two 
hours, the tip links remained intact if the stereocilia were not forced into disarray. In contrast, the smallest change in intrahair spacing on a cell resulted in significant tip link breakage. If this linkage is involved in transduction, such disruption may very well impair the function of the hair cell.

Studies previously mentioned have focused primarily on the effects of overstimulation due to very high noise levels. Research by Bohne (1976) examined damage to the Organ of Corti due to exposure to lesser intensities. Namely, chinchillas were exposed for either two or nine days to an octave band of noise, its center frequency being either $.5 \mathrm{kHz}$ or $4 \mathrm{kHz}$. The intensities of the stimuli were all either less than $80 \mathrm{~dB}$ SPL, or $80 \mathrm{~dB}$ SPL and greater. In the low-intensity group, there was minimal cell damage. In those exposed to intensities of $80 \mathrm{~dB}$ or greater, there was some loss of both hair cells and supporting structures, especially in the basal region of the cochlea. Understandably, greater damage occurred in those exposed for nine days than for two. In addition, presentation of the low frequency $(.5 \mathrm{kHz})$ band resulted in greater damage to the basal region than the apical region. All of these results were consistent with findings in humans, in that greater threshold shifts occur with exposures to higher intensities, for longer duration, and are most detectable in the higher frequencies.

Research has also been conducted to assess threshold shifts in response to noise exposure in chinchillas with pre-existing noise-induced hearing losses (Mills, 1973). Four of the animals, hearing-impaired due to previous noise exposure, were exposed to an octave-band noise with a $4 \mathrm{kHz}$ center, presented at $80 \mathrm{~dB}$ SPL for 5 days. They were then removed for auditory assessment of threshold shift, and returned to their cage. 
Controls were 16 chinchillas with normal hearing. They were exposed to $80 \mathrm{~dB}$ SPL for periods between two and nine days. Threshold shifts of the hearing-impaired subjects were less than those of the controls, no matter what the duration of exposure was. The amount of shift was dependent upon the pre-existing loss. The greater the loss, the lesser the shift, and vice-versa. However, at $2 \mathrm{kHz}$, the shift was 15 to $20 \mathrm{~dB}$ greater in the two with the greatest pre-existing losses. Following all exposures, both control and experimental subject thresholds returned to pre-exposure levels within six days, thus ruling out evidence of permanent threshold shift. The results appear to show that an ear with sensorineural loss is only as susceptible to the effects of the noise as that of the normal ear. However, more research in the area would need to be done to solidify such a conclusion.

\section{Regulation of Noise Exposure}

According to M. H. Miller, editor of the Council for Accreditation in Occupational Hearing Conservation (CAOHC) Manual of 1985, federal regulations regarding occupational noise exposure "...were issued under the authority of the Walsh-Healey Public Contracts Act of 1935 and reported in the Federal Register on May 20, 1969" (p. 48). In 1956, Air Force Regulation 160-3 was issued, specifying that in addition to individual audiometric monitoring, hearing protection be recommended if an individual was exposed to noise levels above $85 \mathrm{~dB}$, and definitely to be used in areas where exposures exceeded $95 \mathrm{~dB}$ (Suter, 1988). In 1961 the International Organization for Standards (ISO) proposed a standard suggesting limitation of octave bands centered at frequencies of 500,1000 and $2000 \mathrm{~Hz}$ to $85 \mathrm{~dB}$ for exposures of five hours or more, 
based on a "permissible" temporary threshold shift of $12 \mathrm{~dB}$ at $2000 \mathrm{~Hz}$ (Suter, 1988).

The Committee on Hearing, Bioacoustics and Biomechanics (CHABA) formulated and published a report in 1966 including graphs of curves "representing tolerable levels and durations of octave and third-octave bands of noise" (p. 48). These curves delineated what were referred to as "damage-risk criteria". As described by Suter (1988), these reflected the risk of auditory damage a person was expected to incur as a direct result of being exposed to various intensities and durations of noise.

Further guidelines for noise exposure were published in 1967 by the Intersociety Committee. These were very similar to those recommended in the ISO standard. It was stated that one could approximate the risk curves by increasing noise levels by $5 \mathrm{~dB}$ for each halving of exposure time. That is, while $90 \mathrm{~dB}$ would be permissible for eight hours, $95 \mathrm{~dB}$ would be permissible for a four hour period, as the risk is essentially the same (Suter, 1988).

A 1969 publication by the American Conference of Governmental Industrial Hygienists (ACGIH) proposed noise "threshold limit values". Impulse noise, defined as a noise of short duration and high intensity, such a gunfire, dynamite and firecracker explosion (Yost \& Nielsen, 1985), was to be limited to $140 \mathrm{dBA}$ peak sound pressure level, and eight hour exposures were to be limited to $90 \mathrm{dBA}$. This group (ACGIH) also allowed the $5 \mathrm{~dB}$ increase in SPL per halving of exposure duration (Suter, 1988).

Also in 1969 , regulation to limit noise exposure to $85 \mathrm{dBA}$ by the U.S. Department of Labor occurred. It contained information very similar to the curves and recommendations put forth by the ACGIH. This regulation was (and still is) referred to as 
the Walsh-Healey Public Contracts Act (Suter 1988). This act stipulated that noise levels in the workplace had to be controlled to a reasonable extent to reduce industrial accidents and fatigue, and was applicable to all businesses having annual contracts with the U.S. government of $\$ 10,000$ or more (Melnick, 1985).

In 1970, the Occupational Safety and Health Act (OSHA) was passed, imposing minimum standards to be followed in the development and initiation of industrial hearing conservation programs. In addition, it mandated that application of such standards be required not only of industries having governmental contracts, but all those involved in interstate business. The National Institute for Occupational Safety and Health (NIOSH) was formed to oversee activities regarding research on occupational health and safety issues such as these (Suter, 1988).

The hearing conservation portion of the 1970 Occupational Safety and Health Act (also referred to as the Williams-Steiger Act) was taken from the 1969 revision of the Walsh-Healey Public Contracts Act (Lipscomb, 1988). It required employers to use viable administrative and/or engineering methods to limit employee noise exposure to specified levels. If these methods could not reduce levels to those specified, the employers were required to provide employees with hearing protective devices, and an effective hearing conservation program was to be administered. In addition, impulse noise "should" not exceed $140 \mathrm{~dB}$ peak SPL (though reportedly not enforced).

In 1972, NIOSH wrote a "criteria document" based on their research findings (Suter, 1988). Here, it was recommended that the permissible exposure level of $90 \mathrm{dBA}$ be reduced to $85 \mathrm{dBA}$. In addition, it also recommended requirements for record 
keeping, audiometric evaluation of employees, hearing protection and employee notification of test results

Next, OSHA formulated a "Standards Advisory Committee" (SAC), comprised of individuals representing organized labor, state and federal government, affected industries, as well as professionals representing the public. After deliberating over the NIOSH recommendations, the SAC made the recommendation to the Secretary of Labor that the permissible exposure level continue to be $90 \mathrm{dBA}$. However, audiometric evaluation and hearing conservation methods were to be employed when average exposure levels reached $85 \mathrm{dBA}$. Essentially, the cost of engineering controls to reduce levels to $85 \mathrm{dBA}$ were thought to be too great, given the economic climate at the time (Suter, 1988).

In 1974, OSHA published a proposal in the Federal Register setting limits on occupational noise exposure and detailing audiometric testing requirements. This proposal lead to significant disagreement and debate due to its stringent requirements and perceived cost. Consequently, an amendment to the standard, 29 CFR Part 1910.95 was published, outlining the essential components and procedures of an approved hearing conservation program, to include measurement of exposure levels, audiometric monitoring of employees, documentation, and safety education of employees. These requirements were further deliberated, and agreed upon provisions were to become effective in 1981 (Melnick, 1985).

On January 16, 1981, The Hearing Conservation Amendment (HCA) was published in the Federal Register as a final standard. A grace period was granted for employers to comply, setting the effective date of enforcement to April 15, 1981. 
However, this amendment was targeted by newly elected officials because of the assumed cost to American business. The result was yet another delay of the Hearing Conservation Amendment's effective date. Various deliberations ensued, and finally, on March 8, 1983, the entire revised Hearing Conservation Amendment was published in the Federal Register, and became legally effective shortly thereafter (Lipscomb, 1988).

\section{Damage Risk Criteria}

Criteria used to analyze one's risk of incurring auditory damage due to noise exposure is based on sound levels, frequency, and distribution of occurrence (Lipscomb, 1988; Melnick, 1985, 1991; Yates, Ramsey \& Holland 1976). Thus, damage risk is based on the employee's overall exposure to occupational noise. Referring to a 1971 passage by Robinson, D. W. Burns (1973) defines "risk" in general terms as being "the percentage of a population whose hearing level, as a result of a given influence, exceeds the specified value, minus that percentage whose hearing level would have exceeded the specified value in the absence of that influence, other factors remaining the same" (p. 280).

Referring to ISO (1971) standard R1999: Assessment of occupational noise exposure for hearing conservation purposes, Burns (1973) gives the definition with respect to hearing handicap: "The difference between the percentage of people with impaired hearing in a noise-exposed group and the percentage of people with impaired hearing in a non-noise-exposed (but otherwise equivalent) group" (p. 280).

Two damage-risk criteria systems are in use presently (Lipscomb, 1988). These are the Occupational Safety \& Health Act (OSHA), and the International Organization for Standards (ISO) document 1999-1975. The ISO document is used primarily in Europe, 
while U.S. industries follow the OSHA regulations, which must be adhered to by law. Both systems apply to long-term occupational noise exposure levels. However, there are two distinct differences between these standards. First is the time/intensity exchange rate, referring to the aforementioned permissible decibel difference when halving the exposure time. OSHA utilizes a $5 \mathrm{~dB}$ exchange rate, in which case $90 \mathrm{~dB}$ is permitted over an eight hour period, and $95 \mathrm{~dB}$ is permitted for only half that long, a total of four hours. The exchange rate utilized by ISO standards is $3 \mathrm{~dB}$.

The other difference between the OSHA and ISO standards is that OSHA delineates the maximum allowable sound level for a specified period ( 8 hours), while ISO permits calculation over any time period. Therefore, industries following OSHA rules must control peak levels in the environment while those under ISO ruling need not comply.

\section{Current Criteria and Guidelines}

Presently in U.S industry, OSHA standards are utilized in managing the exposure levels of employees. The following is a brief outline of the requirements, as stated in Suter, 1988:

If an employee's time-weighted average (TWA) exposure levels over an 8 hour period equal or exceed $85 \mathrm{dBA}$, a hearing conservation program must be made available. Re-assessment of exposure levels must occur if equipment is changed or if the type of work done produces a significant increase in sound levels. Assessments must be made of areas where intermittent, impulsive or continuous noise ranges from 80 to $130 \mathrm{dBA}$. Employees must be permitted to observe such assessment procedures, and be made aware 
of their personal exposure levels.

Employers must provide a baseline audiogram within one year of an employee's exposure to $85 \mathrm{dBA}$ or greater, and annual evaluations thereafter. These tests are to be administered by trained individuals and overseen by a certified audiologist or physician, in test rooms where background sound levels meet or exceed 1969 American National Standards Institute (ANSI) standards, with appropriately calibrated equipment.

If an employee is exposed to greater than or equal to $90 \mathrm{dBA}$ TWA, hearing protection is mandatory. If exposed to 85 to $89 \mathrm{dBA}$ TWA, a variety of suitable hearing protection devices must be offered, but the wearing of such is not mandatory. The employee is permitted to choose which type he or she prefers to wear.

For those exposed to noise levels equal to or greater than $85 \mathrm{dBA}$ TWA, hearing conservation programs must include annual training and education. This is to include information on the effects of noise on one's hearing ability, the reasons for and methods involved in audiometric testing, as well as the appropriate selection, fitting and use of hearing protection devices. Employers must keep organized records of all sound measurements taken, employee audiograms, calibration procedures and results, and test room sound levels. In addition, these records are to be made available to all employees upon request. Employees exhibiting significant threshold shifts (equal to or greater than an average of $10 \mathrm{~dB}$ at 2000,3000 and $4000 \mathrm{~Hz}$ ) are to be informed of such results in writing, to receive counsel regarding the use of hearing protective devices, and referred to a professional if deemed necessary.

Hearing Loss Associated With Hearing Aid Use 
As early as 1939 , the subject of potential exacerbation of hearing loss due to hearing aid use was addressed. A review of studies focusing on this topic area reveals that there were mixed opinions as to whether the amplification provided by hearing aids can actually cause further hearing loss.

Holmgren (1939) inexorably stated his conviction that as long as the SPL output of a hearing aid did not reach the threshold of feeling, nor was it generating any distortion products, the aid would not possibly cause deterioration of a patient's hearing. His argument was that the use of an aid may in fact have the opposite effect. He reportedly had heard comments from patients whom, after having used aids for some time, could not only hear better with the aids, but felt that they heard better than before, even when not wearing the aids. Holmgren also pointed out the psychological effects of hearing loss and aid use, which in his opinion, were the reason that amplification was thought to cause further deterioration of hearing. He said that it was due to the wearer being able to carry on conversation with others at a further distance than without the aid, noting that others need not raise their voices anymore. Once accustomed to this, subsequent removal of the aid revealed how hearing impaired the person actually was. This in Holmgren's opinion, was interpreted as greater loss caused by the aid itself.

Naunton (1957) reported a preliminary investigation on the possibility of the aid wearer's remaining hearing being damaged due to amplification. He examined the audiological records of nearly 1500 adults who had been fitted with Medresco hearing aids (provided by the English government). Study subjects were selected if their records included a pre-aided audiogram, with "measurable" hearing at .5, 1, 2 and $4 \mathrm{kHz}$. In 
addition, they had to have never used an aid prior to issue of the Medresco aid, no aural surgery, and no evidence of otitis media at the time of the fitting or thereafter. A comparison of pre- and post-aided auditory threshold was made, and statistical analysis made of any changes noted. The author states that when considered at the $5 \%$ level of significance, the analysis revealed that no significant change had occurred in aided ear thresholds. It was also mentioned that some subjects appeared to have shown some improvement in hearing in the aided ear, but this, too, failed to reach significance at the $5 \%$ level. No mention was made as to the type and level of noise exposure these subjects were exposed to while wearing the aids, nor was there any detail as to the output of the test aids. Therefore, the statement that amplification appears to have little or no effect on the user's residual hearing holds little value scientifically. More detail and further research are mandated in order to make such a statement.

Barr \& Wedenberg (cited in Rintelmann \& Bess, 1977) monitored hearing levels in 84 hearing-impaired children fitted with hearing aids. Subjects were divided into two groups, those with endogenous (hereditary) loss $(\mathrm{N}=40)$, and those with exogenous (acquired) loss $(\mathrm{N}=44)$. The exogenous group was then sub-divided into three subgroups: 1) Rubella, 2) Perinatal Accident and 3) Meningitis. All subjects wore their hearing aids on a regular basis at school and at home. Over one-half of the endogenous cases ( 22 total) had some progression of loss, which the authors stated was most likely not due to aid use, but most likely due to hereditary factors. Of those in the exogenous group, the only sub-set which presented as having some progression of hearing loss was the meningitis group, in which all subjects showed such progression. However, these 
results are very questionable, due to the fact that some of them had been treated with dihydrostreptomycin, an aminoglycoside antibiotic which has been reported to cause great damage to the cochlea in patients (Northern \& English, 1991).

The authors stated that it was impossible to determine whether the change was due to the hearing aid use or the medication. They should have divided these subjects into yet another sub-set, those who did, and those who did not receive this medication. These authors made the conclusion that there was insufficient evidence to infer that hearing aid amplification was the cause of further deterioration of hearing. This conclusion simply cannot be made, considering the issue of potential ototoxicity. Were these subjects subdivided as suggested, there may have been some audiological change which could be attributed to amplification, but a separate study would now be required.

Bellefleur \& VanDyke (1968) reported on threshold changes of 58 profoundly hearing-impaired children who had worn "high-gain amplification" for a period of 8 to 10 years. These subjects were divided into two sub-groups. The "known" group $(\mathrm{N}=25)$ included those who had worn their hearing aid in the same ear for this period. The "unknown" group $(\mathrm{N}=33)$ included subjects whose aided ear was not determined, but a prediction of which was made based on threshold changes found in the study. Hearing deterioration was calculated by subtracting the baseline pure tone average from the final average for each ear, then subtracting the unaided ear average from that of the aided ear. Two frequency ranges were compared, that of 125 to $500 \mathrm{~Hz}$, and 500 to $4000 \mathrm{~Hz}$. Results revealed that there were no significant changes at the $1 \%$ confidence level in either group. Thus, the conclusion was made that the high gain amplification worn by 
these children had no significant deleterious effect. It was noted, however, that these subjects had profound pre-existing losses, and may have been wearing their aids set at levels "...which are comfortable to them and, therefore, below the danger point" (p. 347). It is difficult to discern some aspects of this study, because details of the hearing aid gain and output were not given, and neither were the noise levels to which the subjects were exposed. Other aspects of the study appear reliable and repeatable, and it would be interesting to replicate it using subjects with mild and moderate hearing losses.

In 1970, Madell \& Asp (cited in Rintelmann \& Bess, 1977) looked at the effect of amplification on eighteen bilaterally hearing-impaired pre-schoolers. Fifteen of these had severe or profound loss in their better ear, and three had moderate to moderately severe loss in their better ear. All subjects reportedly wore hearing aids regularly, during aural rehabilitation and at home. Thresholds were compared prior to the prescription of the hearing aids, then at three month intervals over a period of six months. The information obtained from the comparison revealed that no significant threshold changes occurred which could be attributed to hearing aid use. It was suggested that some change can occur, however, and that children receiving amplification be periodically re-evaluated to monitor their auditory status. Again, no information was given regarding the hearing aids, so little can be concluded regarding output levels and potential for hearing deterioration. In addition, the subjects were severely to profoundly impaired, and the period over which thresholds were monitored was very limited. Aids worn at high output levels for several years may cause further auditory decrement that this study could not address.

Titche, Windrem \& Starmer (1977) stated that hearing aid use over a prolonged 
period did not result in progression of loss in the aided ear. They reported on their study of 261 patients at a Veteran's Hospital who had been fit with a variety of hearing aids over a period of 10 years. The aids reportedly had gains ranging from 36 to $72 \mathrm{~dB}$, and maximum power outputs of 110 to $142 \mathrm{~dB}$. The authors looked at differences in the progression of loss in the aided ears versus that in the unaided ears over time. If the threshold in the aided ear increased more than that of the unaided ear, a "positive" result occurred. If the loss progression was greater in the unaided ear, a "negative" result occurred. Comparisons were made for three sub-groups: 1) all subjects, 2) patients with conductive loss and 3) patients with sensorineural loss. For sub-groups "all" and "sensorineural", the changes were not significant. In the "conductive" sub-group, the threshold shift at $4 \mathrm{kHz}$ was significant, while other changes were noted as being not significant.

Reilly, Owens, Uken, McClatchie \& Clarke (1981) reported on a study which addressed progressive hearing loss in children. They considered hearing aid use, loss etiology, and the time relation between the fitting of the aid and the actual progression of the loss. They reviewed cases from three hearing and speech centers where patients' hearing had been worsening over time. Subjects with sensorineural losses who, over a period of at least two years, had presented as having at least a $15 \mathrm{~dB}$ change for the worse at a minimum of two frequencies were included in the study. A total of 45 files were found to match these criteria. Results demonstrated that hearing aid use was not consistently related to loss progression, though it appeared to be implicated in a few cases. To what degree, it was stated that "...hearing aid use was not implicated in 31 
$(69 \%)$ of the progressive loss subjects, questionably implicated in nine $(20 \%)$ and probably implicated in five cases (11\%)" (p.332). The actual gain and output maximums of the hearing aids were not available, because electroacoustic measurements of such were not made prior to use. Also, the amount of temporary threshold shift caused by the aids was not formally addressed in this report.

The potential long-term effects of amplification was also researched by Gelfand, Silman \& Ross (1987). Subjects included 86 adult males with bilateral sensorineural loss. Forty eight of these were monaurally aided, 19 were binaurally aided, and 19 were binaurally unaided. The monaural group was divided into subgroups, 19 monaurally aided, and 19 monaurally unaided ears.

Comparisons were made of $\mathrm{PB}$ and pure-tone results prior to being aided, and then a minimum of four years later. Some threshold shift was noted at all frequencies for all groups, but reportedly were not statistically significant. In fact, the changes in PB scores, while insignificant for the binaurally unaided, binaurally aided and monaurally aided, were actuaily significant for the monaurally unaided group. This result suggested the possibility of auditory deprivation in the unaided ear because of a lack of stimulation (hearing loss and no amplification). The authors stated that the reportedly insignificant pure tone threshold shifts suggested that there was no acoustic trauma which could be attributed to amplification. However, the decibel input levels, the gain and maximum power output of the aids were not given. Therefore, this report did not provide a clear explanation of subject noise exposure due to the amplification. Without such information, important questions and considerations are left unanswered. 
While the aforementioned case studies resulted in some auditory decrement that could be associated with overamplification by hearing aids, the primary conclusion was that such changes were not statistically significant. Contrary to these findings, many other researchers in the field have reported that overamplification can, indeed, lead to significant threshold shifts.

In 1953, C. E. Kinney reported his findings of repeat examination performed on 461 subjects, stating that 445 (96.5\%) of the subjects presented as not having significant changes in hearing thresholds. However, $16(3.5 \%)$ did have increased thresholds. Though a more detailed report on these 16 subjects was to have been put out at a later date, the author did state that the threshold progression was extensive, and was not occurring until a hearing aid was worn. The loss progression was greater in the aided ears than in those which were unaided. His primary conclusion was that just as it is known that exposure to high levels of noise causes cochlear damage in the normal ear, it was also possible that this may be true in the case of the previously uninjured cochlea, and that further research in this area was necessary.

Harford \& Markle (1955) detailed the audiological changes in a young girl with severe congenital sensorineural loss who wore a hearing aid in one ear. Following three years of amplification, aided ear thresholds were significantly increased, ranging from 10 to $25 \mathrm{~dB}$ poorer. Unaided ear thresholds, however, remained at their original level. The researchers alternated the hearing aid from one ear to the other over a period of four months, and tracked threshold changes. In each case, the aided ear presented as having decreased acuity, and the unaided ear returned to its previous level of acuity. 
Kinney (1961) observed 178 children with diagnosed progressive sensorineural losses. Those wearing moderate gain aids had threshold shifts of 10 to $15 \mathrm{~dB}$, while the children wearing high gain aids averaged shifts of $20 \mathrm{~dB}$. Though some authors may question basing any judgment on studies run on those with "progressive" losses, this researcher noted that loss progression was more prominent in the aided ears than in the non-aided ears. In addition, the degradation could be traced back to the time when the hearing aids were originally prescribed.

In 1961, Sataloff wrote of a seven year old boy who had been fitted with a hearing aid on one ear at age three. (Unfortunately, the type and characteristics of the aid were not given in the text). The child reported that he was having trouble hearing, and audiological results revealed that acuity in the aided ear had deteriorated. Thresholds had increased by $50 \mathrm{~dB}$ or more at frequencies between 250 and $4000 \mathrm{~Hz}$. The hearing aid was removed, and within three months, thresholds returned to pre-amplification levels. The aid was alternated on and off the same ear over the next two years. Each time the aid was worn, thresholds increased. When removed, thresholds returned to pre-aided levels. This entire time, thresholds of the unaided ear remained unchanged. Based on these results, Sataloff believed that the aid was responsible for the changes.

Macrae \& Ferrant (1965) assessed the deleterious effect of using high and moderate powered aids on children via comparison of auditory acuity changes in aided versus unaided ears. A total of 87 children were included, 34 of which used TB (moderate power) aids, and 53 used T5 (high power) aids. The hearing aids were used for periods ranging from 10 months to 10 years, two months. Subject criteria included a 
bilateral sensorineural loss of 50 to $90 \mathrm{~dB}$ (approximately the same in each ear) at the time of the fitting, no conductive component nor history of recurrent otitis media, equal to or greater than six months' use of the aid unilaterally, one audiogram and an ENT's professional opinion of loss etiology.

In the $\mathrm{T} 5$ wearers, average threshold increases at all frequencies were significantly greater in the aided ears than in the control, or unaided ears. The average thresholds in the TB wearers were increased to a significant level at two frequencies only, 500 and $4000 \mathrm{~Hz}$, in the aided ears. Further comparisons revealed that in the high powered aid wearers, more deterioration occurred in ears with better initial acuity, and the longer the aid was worn, the greater the detriment. In the moderate powered aid wearers, more deterioration occurred in the ear with better initial acuity, while the length of time worn was insignificant.

The authors stated that whether the loss was endogenous or exogenous appeared not to be significant, and the degree of deleterious effect appeared to be dependent upon the aid's maximum power output (MPO), acoustic gain, the length of time worn, and amount of pre-existing hearing loss. In addition, it was suggested that people wearing aids due to sensorineural hearing loss should not wear them in areas with high levels of ambient noise.

Ross \& Truex (1965) presented two cases focusing on clinically unexplained acuity degradation when powerful hearing aids were used. Case one centered on a 13 year old boy with moderate to severe loss whose right ear was fitted with an aid having an MPO of $139 \mathrm{~dB}$ (according to manual specifications). Due to further difficulty in school, 
he was re-tested. Pre- versus post-aid fitting results revealed that while there was no appreciable change in the left (unaided) ear, the right (aided) ear thresholds were 25 to 35 $\mathrm{dB}$ poorer across all frequencies. His left ear was then fitted with an aid with an automatic volume control (AVC) circuit, and the right was left unaided, which was reported to have been successful.

Case two centered on a 14 year old boy with severe bilateral loss, aided in his left ear at age 4 years. (The gain and output of this first aid was not given). At age 8, the audiologist switched to an aid with an MPO of $139 \mathrm{~dB}$ (manufacturer's specifications). At age 13 , he began having more difficulty. Repeat tests revealed significant change for the worse in the aided ear. Slight differences in right ear thresholds were thought to be due to different audiometers and testers, but degradation in left ear thresholds was too great to be similarly explained. Again, an AVC aid was put on his right ear, and was said to have been successful by causing no further deterioration in hearing acuity.

Ross \& Lerman (1967) wrote a review of the literature as well as results of their own investigation regarding the effects of amplification on residual hearing. Their study looked at pre- and post-aided thresholds of 18 subjects aged 7 to 19 years with symmetrical bilateral sensorineural losses. After 5 years of aid use, thresholds were compared. Positive and negative changes in acuity for each ear were added to get the "relative shift". For example, if the aided ear shows a $15 \mathrm{~dB}$ shift for the worse, and the unaided ear shows a $10 \mathrm{~dB}$ shift for the worse, the "relative shift" is positive $5 \mathrm{~dB}$. Positive differences occurred at 250,500, 1000 and $2000 \mathrm{~Hz}$, while slight negative differences were noted at 4000 and $8000 \mathrm{~Hz}$. Nine subjects had the most shift, while the 
other nine had little or no (negative) shifts. Average relative shift at 500, 1000 and 2000 $\mathrm{Hz}$ were found to be significant. The highest correlation found was with the average relative shift and average loss at fitting time, indication that the subjects with the greatest amount of pre-existing loss showed the greatest shift (the exact opposite of Macrae \& Ferrant, as well as the researchers' expectations).

The authors summarized their findings by saying that shifts due to hearing aid use was indeed possible. The shifts seemed to be related to the number of hours the aid was worn, the amount of pre-existing hearing loss and possibly to the MPO of the aid. They recommended that the MPO's be limited to $130 \mathrm{~dB}$ SPL or below, and that aided children receive frequent follow-up evaluations.

Macrae (1968) wrote of temporary threshold shift (TTS) and subsequent recovery from it following the use of moderate and high gain hearing aids. This study focused on threshold shift in 134 children aged 5 to 18 with losses ranging from mild to severe. Hearing aids with MPO's of 115 to 130 were worn for periods of at least one year, and shifts were observed and analyzed. His results led to the conclusion that such levels of amplification can produce substantial amounts of TTS over a range of frequencies. It was also noted that the length of recovery time in the majority of the aid users was greater than that of subjects with normal hearing.

Macrae (1968) also researched and reported on the deterioration of hearing in children previously diagnosed with sensorineural hearing loss, comparing four different types of hearing aids. The low powered aids included the 5TA, having an MPO range of 115 to $117 \mathrm{~dB}$ SPL and the 5TB, with an MPO of 117 to $119 \mathrm{~dB}$ SPL. The moderate 
powered aid was the Calaid TB, having an MPO of 119 to $124 \mathrm{~dB}$ SPL. Finally, the high power amplification was provided by the Calaid T5, having an MPO ranging from 122 to $130 \mathrm{~dB}$ SPL. Respective gain ranges of each aid type were 30 to $36 \mathrm{~dB}, 40$ to $45 \mathrm{~dB}, 45$ to $52 \mathrm{~dB}$ and 55 to $68 \mathrm{~dB}$ (SPL).

Comparison of pre- and post-amplification audiograms revealed that the use of powerful (120 to $130 \mathrm{~dB}$ MPO) hearing aids had a definite detrimental effect on the children's residual hearing, while the less powerful aids (115 to $119 \mathrm{~dB}$ MPO) did not show an adverse effect on their thresholds. These results confirmed previous findings that in cases of sensorineural deafness, the fitting and use of "high-powered" aids definitely has a detrimental effect upon residual hearing. In addition, the consequences of hearing aid use in cases of exogenous versus endogenous loss appeared to be similar, except that the losses of exogenous nature worsened consistently to a greater degree than did those of endogenous nature. Finally, though some small amounts of deterioration were noted in the unaided ears, it was less in those presenting as having greater loss initially.

In an attempt to determine whether hearing aids could damage the wearer's hearing, Roberts (1970) reported that of 278 children examined over a 3 year period, three revealed evidence of poorer hearing in the aided ears. The findings of one case study were detailed in which a child with a bilateral moderate sensorineural loss was fitted in one ear with a hearing aid, though no hearing aid specifications were given. Nine months later, follow-up tests revealed significant loss ( 25 to $50 \mathrm{~dB})$ in the aided ear, most apparent in the 2 to $8 \mathrm{kHz}$ range. The aid was removed, but the next one-year follow-up revealed no improvement. Thus the loss was considered to be permanent. 
The author also mentioned that this boy's sister was diagnosed with similar loss and etiology, but was not fitted with an aid. Over the next 14 months, she had only $5 \mathrm{~dB}$ of deterioration over the entire range of frequencies tested. These results suggested that fitting children with this type of progressive loss can cause further deterioration of hearing acuity in the amplified ear, although noted as being relatively uncommon an occurrence.

In 1975 , Jerger \& Lewis wrote of a nine year old girl with severe bilateral sensorineural hearing loss due to rubella. At age three her left ear was fit with a hearing aid providing an MPO of $135 \mathrm{~dB}$. Following one year of use, her audiogram revealed that the left ear thresholds had increased by approximately $20 \mathrm{~dB}$, while the right ear thresholds were unchanged. It was noted that these authors felt that the use of children as research subjects was not preferable due to the preponderance of fluctuations in their thresholds caused by upper respiratory infection, as well as their inability to respond accurately to questions regarding hearing aid use and auditory acuity change.

Nevertheless, they suggested that due to these results, and other similar results found in the literature, clinicians exercise caution when fitting kids binaurally, and take this on a case-by-case basis.

Markides (1976) monitored thresholds of four groups of "deaf" children over three years. Losses were bilateral sensorineural, and the children were reportedly either born deaf or lost their hearing within the first few years of life. Group A wore commercial aids (unnamed in the text) with MPO's of 130 to $136 \mathrm{~dB}$ SPL. Group B's aids had MPO's of 116 to $128 \mathrm{~dB}$ SPL. Group C went completely unaided during the study, and Group D wore binaural body aids providing the same output as those of group B. 
A comparison of all baseline-to-final thresholds was made, and it was found that when averaged, there were not significant changes which occurred, though results tended to show a slight improvement ( 2 to $3 \mathrm{~dB}$ ) in hearing acuity of the aided ears, while unaided ear thresholds revealed some degradation ( 0 to $2 \mathrm{~dB})$ at all frequencies tested. However, when analyzed on an individual basis, four of the aided children presented as having a decline in hearing acuity of 10 to $15 \mathrm{~dB}$ bilaterally, especially at $4 \mathrm{kHz}$.

When all subject results were compared, the threshold changes were very small, and insignificant statistically. These could have been due to tester bias or to deviations in test protocol. The environments where the aids were worn were not detailed and aids may not have been worn consistently by the subjects. However, the threshold shifts noted in individual cases were significant, and consistent with several of the other authors previously noted.

Laquillon (cited in Titche et al., 1977) reported that a study of 80 children wearing hearing aids revealed $7.5 \%$ who suffered further hearing loss attributable to hearing aid use. Again, no detail regarding aid specification nor ambient exposure levels was given so no definitive conclusions other than the change noted can be made.

A 1970 case study presented by Kasten \& Braunlin (cited in Rintelmann \& Bess, 1977) focused on a 10 year old girl diagnosed with bilateral moderate sensorineural loss. One ear was fitted with an aid providing gain of $39 \mathrm{~dB}$ and an MPO of $120 \mathrm{~dB}$ SPL. After wearing it for 14 months, marked deterioration was noted in the aided ear, but not in the unaided ear. The aid was removed, and after 7 weeks, her hearing showed substantial improvement ( 20 to $30 \mathrm{~dB}$ ) in the ear that had been aided. The aid's MPO was 
reduced, it was periodically alternated between ears, and the deterioration did not occur. Based on these results, it appeared that avoiding constant overamplification by interspersing aid use with quiet periods can help in controlling the potential for further hearing loss.

Humes (1978) attempted to assess the potential for temporary threshold shift due to overamplification by testing his own TTS. He conducted two experiments in which he, a young adult with normal hearing, wore a moderate gain hearing aid in both a loud setting, and that of a college classroom. The loud setting involved turning the hearing aid volume full-on, which provided output of 113 to $132 \mathrm{~dB}$ SPL, sitting one meter from a loudspeaker, and listening to $70 \mathrm{dBA}$ of taped four-talker speech babble for a total of 57 minutes. In both cases, TTS was reported as "considerable", noting a $40 \mathrm{~dB}$ shift immediately following exposure in the loud setting. It took over 24 hours for his thresholds to fully return to their original level.

Further research involving Humes and his colleague Bess took place and was reported in 1981 . They made electroacoustic measurements of the outputs produced by three hearing aid settings. Reported gains ranged from 32 to $63 \mathrm{~dB}$ SPL, with SSPL-90's ranging from 107 to $131 \mathrm{~dB}$. Thus the speaker output (with a $60 \mathrm{~dB}$ input) ranged from 94 to $127 \mathrm{dBA}$. Each aid was connected to an HA-2 2-cc coupler and placed in a soundproof booth, one meter from the speaker. Tape-recorded cafeteria noise (speech babble) was set to average $60 \mathrm{dBA}$ at the hearing aid microphone. Volume control settings were full-on during all measurements.

Using W. Kraak's formula (Humes, 1981) for prediction of hearing loss from 
previous research, the following statements were made. First, an output of $94 \mathrm{dBA}$ would cause measurable noise-induced permanent threshold shift at $4 \mathrm{kHz}$ in a person with normal hearing after 579 days of hearing aid use. Second, permanent loss of $55 \mathrm{~dB}$ at 4 $\mathrm{kHz}$ would result after 15.86 years of daily use. Finally, with an output of $127 \mathrm{dBA}$, the permanent shift would begin in a normal-hearing person after only 12.9 days, and would result in a permanent shift of $55 \mathrm{~dB}$ in only 129 days.

Few conclusions can really be made from this study, other than that thresholds are temporarily increased when exposed to high levels of amplification. To assess the probable consequences of amplifying such noise, it would have been more appropriate to make measurements utilizing noise which actually occurs in a hearing aid wearer's environment. Static measurements of speech babble for such a short time does not include integration of fluctuations which occur in a listener's environment.

In addition, the measurements of hearing aid output were made using a 2-cc coupler, which is not representative of the actual output received by the human ear. It would have been much more accurate to make similar measurements using a Zwislocki coupler and a Knowles Electronic Mannequin for Auditory Research (KEMAR).

Secondly, the researchers wanted to determine the possible levels to which hearing aid wearers might be exposed, given certain ambient levels, and what hearing loss one might expect to incur. They used Kraak's formula for time integral of threshold shift to calculate this. Based on their mathematics, they hypothesized that if a person's preexisting hearing loss was fit into the calculation, then the level of exposure intensity would have to exceed the amount of their pre-existing loss before any further auditory decrement 
would occur. However, this notion would later be proven inaccurate by Hawkins.

In 1979, Heffernan \& Simons reported on two subjects, both with bilateral symmetrical sensorineural loss, probably congenital. Case A focused on an individual with moderate loss, whose right ear was aided with a body aid. The reported gain (according to the manufacturer specifications) was $45 \mathrm{~dB}$ SPL, and MPO was supposedly $125 \mathrm{~dB}$ SPL. The actual measured MPO peak was $135 \mathrm{~dB}$ SPL. After 7 months, thresholds were retested, revealing that the unaided ear was stable, but in the aided ear both air and bone thresholds had worsened. Air thresholds were 5 to $25 \mathrm{~dB}$ worse, primarily in the low to mid frequencies, and there were no bone-conduction responses at all. The subject went unaided for 14 days, and the retest revealed a return to baseline thresholds (plus or minus $5 \mathrm{~dB}$ ). The subject was subsequently fitted with a behind-theear aid with a gain of $32 \mathrm{~dB}$ SPL and MPO of $115 \mathrm{~dB}$ SPL. Repeat tests showed no decrement.

Case B focused on someone with a mild-to-moderate loss, whose left ear was fitted with a body aid. Here, the reported gain was $45 \mathrm{~dB}$ SPL and the MPO was reportedly $125 \mathrm{~dB}$ SPL. One year later, the unaided ear was stable, but the aided ear had threshold shifts from 20 to $35 \mathrm{~dB}$, primarily in the lower frequencies. This subject also went unaided for 14 days, and retest showed the left ear thresholds had improved to within $10 \mathrm{~dB}$ of baseline. This person was then fitted with a behind-the-ear aid providing gain of $33 \mathrm{~dB}$ and MPO of $108 \mathrm{~dB}$. After one month, left ear thresholds again worsened. The aid was switched to the right ear, and auditory status was monitored over the next 6 months. The right ear remained unchanged, while the left thresholds slowly improved. 
The primary conclusions brought out by these results prompted the authors to state that the maximum power output of hearing aids should be limited to $132 \mathrm{~dB}$ SPL. If the loss is mild-to-moderate, it should be limited to $120 \mathrm{~dB}$ or less.

Hawkins (1982) wrote of a case report detailing the exacerbation of hearing loss in a 29 year old woman. She was fitted in 1969 with an aid on her right ear which had an SSPL-90 of $122 \mathrm{~dB}$, with a maximum power output of $131 \mathrm{~dB}$ SPL. After 8 years, (1977) she felt that this aid was not powerful enough, so she was fit with more gain. The new aid's SSPL-90 was $127 \mathrm{~dB}$, and the maximum peak was $135 \mathrm{~dB}$. At no time were the outputs uncomfortable to her. Considerable decrease in hearing ability began during that year, in the aided ear only. Threshold shifts by 1981 ranged from 30 to $45 \mathrm{~dB}$ over the frequencies tested, with that at $4 \mathrm{kHz}$ exceeding the limits of the audiometer.

Comparatively, no appreciable change occurred in the unaided ear, except for $15 \mathrm{~dB}$ at 1 $\mathrm{kHz}$, and $10 \mathrm{~dB}$ at $2 \mathrm{kHz}$.

As of 1981, she wore an aid in the left ear, providing a maximum output of 115 dB SPL. No significant change was noted. The author stated that based on these results, it was apparent that damage can occur when the output of an aid is below the patient's uncomfortable levels (UCL's). The issue is not the levels of discomfort, but the sound pressure level actually arriving at the cochlea.

Macrae (1991) reported on data regarding the permanent threshold shift (PTS) related to hearing aid use by 8 children suffering from severe bilateral sensorineural loss. The children wore one aid only, the other was left unaided. Aid types were the TB, T and T5 from Calaid. Gains were measured using a 2-cc coupler. Average gains were $48 \mathrm{~dB}$ 
for the TB, $56 \mathrm{~dB}$ for the $\mathrm{T}$ and 60 for the $\mathrm{T} 5$ models. Macrae used a one-third octave band filter attached to an integrating sound level meter (dosimeter) to make output measurements. He held the microphone of the dosimeter "close to one of his ears" while walking around an office talking with others, and the street noise coming through an open window was included. One-third octave band levels of this noise were measured and integrated over 10 minutes for each band, and referred to as the "typical input levels". Meanwhile, an estimation of the levels created by each of the hearing aids was attained by adding the 2-cc coupler gain at certain frequencies and volume control settings used by the children, to the one-third octave band levels of the "typical input sound". Then the aided levels generated by the hearing aid worn in each child's ear were estimated by adding the appropriate 2-cc coupler-to-real-ear correction as suggested by Skinner (1988) to the 2-cc coupler levels.

Actual hearing threshold levels increased due to the exposure, but did not have the high-frequency accentuation typically seen in cases of noise-induced shift. Rather, the deterioration in thresholds were generally flat across frequencies. The loss began to occur not long after use of the aids began, and the rate at which the shift occurred was somewhat slower than that which would be seen in an individual with normal auditory acuity. Whereas Humes \& Bess (1981) had hypothesized that in an individual with sensorineural loss, there might be a long delay period between the initial exposure to the noise and the onset of further deterioration of hearing, the results of this study were the opposite. When compared to predictions of threshold shift based on the Modified Power Law of Humes \& Jesteadt, the data were fairly consistent. 
This study involved good planning to determine the effects of overamplification, but there were problems with the execution. The sample of hearing aid users was quite small, limiting the strength of loss data. Actual noise measurements were not made; only averages of some made in an office setting were utilized, which does not necessarily represent that to which the children were exposed during their daily activities. Finally, the researcher did not integrate sound levels over longer periods of time. They actually fluctuate, but here, a constant level of noise was used to come up with the information.

In 1993, Macrae reported on the TTS in a 15 year old girl suffering from severe sensorineural loss in her left ear, and profound loss in her right due to maternal rubella. The MPO provided by her left ear aid was not given, but was reportedly set at the highest setting. Gain was set to 4 , and the highest setting here was 6 , while the volume control was set to just over one-half maximum. Macrae had this girl wear a dosimeter for 80 minutes while in class, the microphone placed on her collar. Her actual exposure period, however, was 4 hours total. The temporary threshold shift in the subject occurred at all frequencies, a greater amount in the mid-frequency range, and on all days tested. The dosimeter recorded and analyzed the input levels in $\mathrm{dBA}$. The author wanted to see if the temporary threshold shift which occurred was predictable using the Modified Power Law of Humes \& Jesteadt, based on her noise exposure while wearing the aid. Macrae also stated that following 8 to 10 hours of hearing aid use, the TTS will probably reach an asymptote, referred to as asymptotic threshold shift (ATS). A comparison of results (both observed and predicted using the Modified Power Law) showed that the similarity of these provided support for the use of the MPL in prediction of TTS caused by excessive 
noise, in those having pre-existing loss.

Notation was made by the author that when noise occurs in a diffuse field, such as the ear canal, it is noted that sound levels at the eardrum are greater than the levels outside the head. Because of this transfer function, levels at each frequency must be increased to predict actual levels at the drum itself. The MPO of the aid did not have much effect on in-the-ear noise levels. It was stated that reduction of the MPO has little effect on the average output unless the aid is in saturation a large proportion of the time. A reduction in gain does not occur when high input levels are infrequent. Reduction in gain itself, by reducing the volume control setting is best, while a reduction in MPO should be secondary. In addition, the author stated that with regard to a "safe" amount of asymptotic threshold shift exists, the higher the threshold, the lower the ATS safety limit. Thus, the greater the hearing loss, the less the noise exposure which is safe. Exceeding these lower amounts may very well lead to more hearing loss, after all. 


\section{CHAPTER III}

\section{METHODS}

Two methods were employed in this study. One involved recorded noise, and the other involved direct measurements.

\section{Method One}

Recordings of noise were made in two environments. The first was made in an industrial manufacturing plant, Sulzer-Bingham, Inc. The second was made in the cab of a locomotive. Noise levels at each location were recorded using a TEAC DAP-20 Digital Audio Tape (DAT) Recorder and DAT tapes, which provided two hours of recorded sound. The microphone used was a Bruel \& Kjaer type 4134 one-half inch free-field condenser microphone. Power was supplied by an ACO Pacific PS 9200 acoustical interface power supply and pre-amplifier.

The first data set was gathered using a two hour tape recording made while standing beside an employee working at a Gisholt T-5 Turret Lathe located in the light bay department of the Sulzer-Bingham industrial manufacturing plant. The recording included the grinding and sanding of metals, air hose blasts reaching levels of $104 \mathrm{dBA}$, and other similar noises. Other machinery is located nearby in the department (Figure 1), and the noise emitted from these is also included in the recording.

The second data set was based on a similar two hour recording of ambient noise 


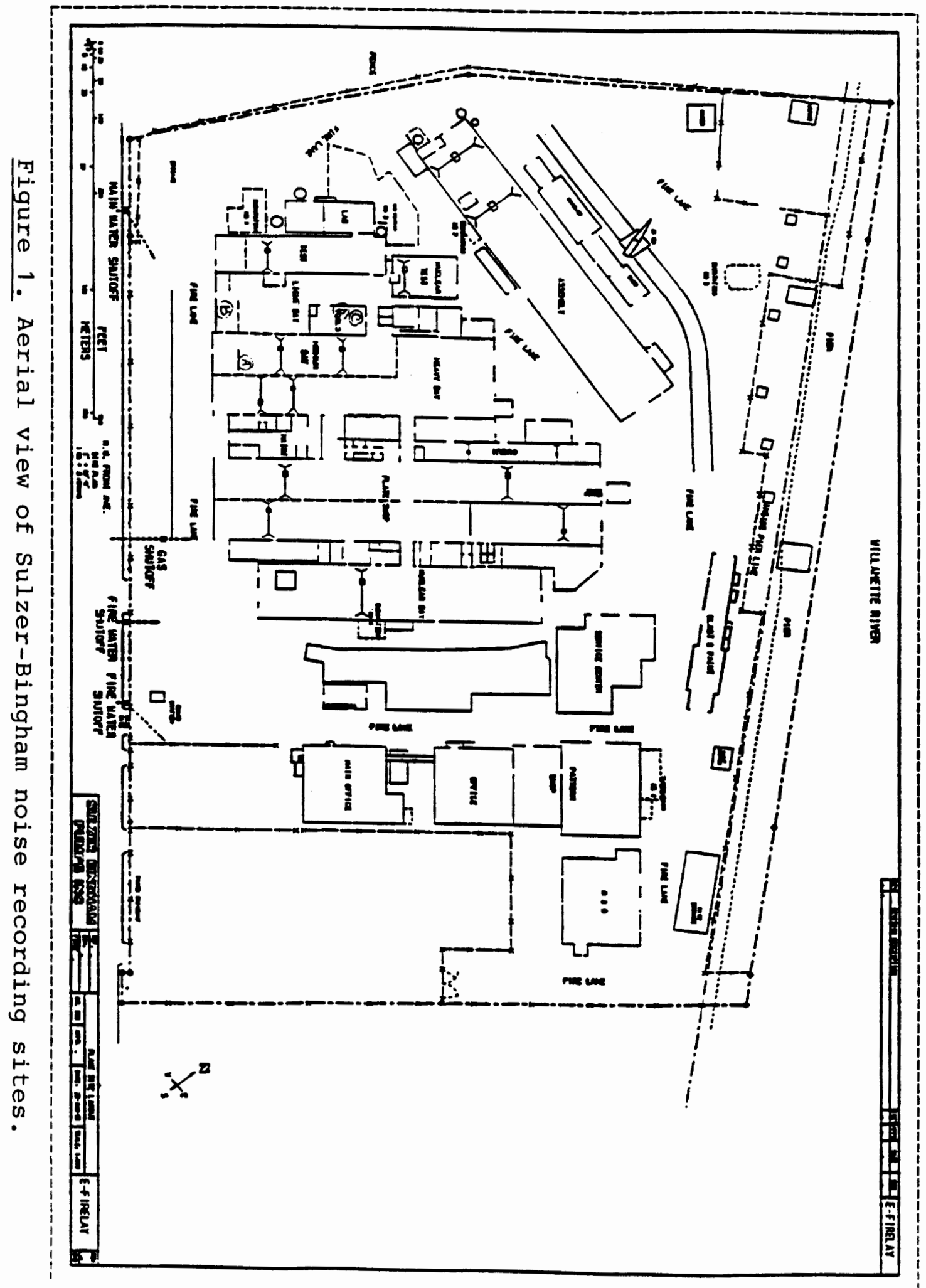


recorded while standing next to the engineer in the cab of the locomotive in a switching yard. These recordings were played back in an acoustic chamber using the TEAC DAP20 recorder. Its output was amplified by an NAD 2240 PE stereo power amplifier and attenuated by a Leader LAT-45 attenuator. The output of the attenuator was routed to a loudspeaker (Maico Instruments) placed in the acoustic chamber. The attenuator was set so that, when averaged over eight hours, the time-weighted average of the taped noise would be between 80 and $84 \mathrm{dBA}$ sound pressure level.

In the acoustic chamber a Knowles Electronic Mannequin for Auditory Research (KEMAR) was positioned so that its right ear was approximately $93 / 4$ inches from the speaker (Figure 2). A Knowles Electronic DB 100 ear simulator (also referred to as a Zwislocki Coupler) was attached to this ear. A Larson-Davis model 2561 random incidence one-half inch condenser microphone was placed within KEMAR's head and attached to the Zwislocki coupler. The microphone was connected by cable to a LarsonDavis 820 Precision Integrating Sound Level Meter. The Larson-Davis 820 sound level meter and microphone were calibrated by a Bruel \& Kjaer pistonphone type 4220 , or a Larson-Davis CA-250 calibrator.

Noise measurements were made for both aided and unaided conditions. The aided condition involved utilizing the taped recordings and a variety of hearing aids providing different amounts of gain. In the aided condition each hearing aid was placed on KEMAR's right ear and the output was routed to the Zwislocki coupler. Five hearing aids were employed, representing gain ranging from mild to high (Table 1).

The electroacoustic characteristics of each hearing aid were assessed using a Frye 


\begin{tabular}{|c|c|c|}
\hline $\begin{array}{c}\text { Teak DA-P20 } \\
\text { Recorder }\end{array}$ & $\begin{array}{c}\text { NAD 2240 PE } \\
\text { Power Amp }\end{array}$ & $\begin{array}{c}\text { Leader LAT-45 } \\
\text { Attenuator }\end{array}$ \\
\cline { 2 - 3 }
\end{tabular}

\section{Acoustic Chamber}

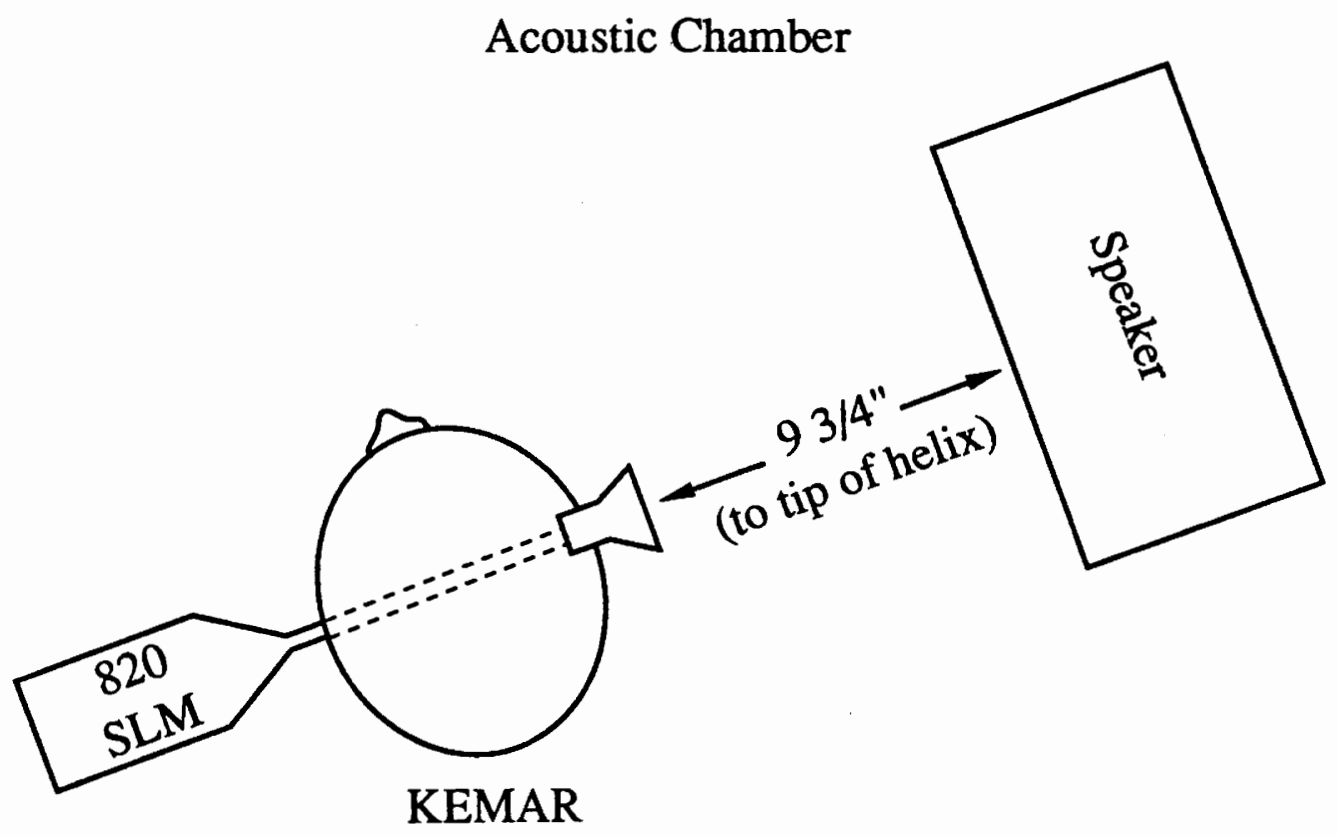

Figure 2. Aerial view of acoustic chamber noise analysis site. 
TABLE I

HEARING AID TYPE, GAIN AND OUTPUT

\begin{tabular}{|c|c|c|c|}
\hline Hearing Aid Type & Avg SSPL-90, dB & Avg Full-on Gain, dB & Reference Test Gain, $\mathrm{dB}$ \\
\hline & & & \\
\hline & & & \\
\hline Starkey CE & 94 & 23 & 17 \\
\hline & & & \\
\hline Audiotone A37 & 100 & 22 & 22 \\
\hline & & & \\
\hline Electone 800 & 104 & 26 & 26 \\
\hline & & & \\
\hline Bausch \& Lomb R6 & 104 & 38 & 27 \\
\hline & & & 47 \\
\hline Widex A18+H & 114 & 47 & \\
\hline
\end{tabular}

Electronics Fonix F20 Hearing Aid Analyzer. During data collection, the aids were set to reference test position, as defined in ANSI S3.22 (1987). This setting is a clinical standard utilized in assessing hearing aid function, gain and output, in relation to manufacturer's specifications. It is meant to approximate the volume control setting that would be used by a wearer of a hearing aid. Once set at reference test position, the volume control wheels were taped to assure stability of gain. Fresh hearing aid batteries were used for each measurement.

When in-the-ear output was being analyzed, DAP Fun-Tak adhesive putty was used to completely seal its connection in the coupler, and if the aid was vented, putty was 
placed in the vent. This was to ensure that the gain of the aid would be similar to that measured during the Frye hearing aid analysis, a procedure which requires that the vent be closed. The behind-the-ear aids were attached to earmolds specifically made to fit in KEMAR's right ear, so putty was not required unless used to seal the vent.

\section{Method Two}

Subjects for this portion of the study included this researcher, and an employee of Sulzer Bingham, Inc. Measurements were made by each individual personally wearing two dosimeters while going about their work or off-duty tasks.

Instrumentation And Procedures. Two dosimeters, both Larson-Davis model 700 were employed for this portion of the study. One unit was used to record and analyze ambient noise levels, while the other was used to record and analyze the amplified version of the ambient noise. This was accomplished by coupling the hearing aid to the microphone of the dosimeter by means of an adapted Frye HA-1 2-cc coupler.

A plastic sleeve was fit over a Frye HA-1 coupler. Silicast silicone elastomer, primarily used to make earmold impressions, was utilized in sealing the in-the-ear hearing aids in the coupler. The in-the-ear aids utilized in this portion of the study included the "mild" gain Starkey CE and the "moderate" gain Bausch \& Lomb R6. In measuring sound levels provided by "high" gain, the Widex $\mathrm{A} 18+\mathrm{H}$ behind-the-ear hearing aid was used. In this case, the tubing was attached to an earmold. The earmold itself was then coupled to the adapted HA-1 coupler, in exactly the same manner as the in-the-ear models.

Prior to making measurements in the field, a comparison was made to determine 
whether or not the adapted coupler significantly altered the frequency response of the dosimeter microphone. That is, I wished to determine if the output measured using the dosimeter's microphone and the adapted HA-1 coupler was similar to that measured with a standard 1-inch condenser microphone and an HA-1 coupler.

Measurements were made comparing the output level in dBA when using the Frye HA-1 2-cc coupler and Larson-Davis 700 dosimeter, with the standard HA-1 coupler and a Bruel \& Kjaer 2203 Sound Level Meter (Figure 3). Pure tones were generated by a Circuitmate FG2 Function Generator. The output of this function generator was attenuated by a Leader LAT-45 attenuator and routed to an EAR-3 insert earphone. For the first data set, this earphone fit into a standard HA-1 coupler, and Fun-tak putty was used to form a seal. The one-inch microphone of a Bruel \& Kjaer model 2203 sound level meter was inserted into the HA-1 coupler. For the second data set, a Frye HA-1 2-cc coupler was utilized, and the one-inch microphone of the Larson-Davis model 700 dosimeter was inserted into the Frye HA-1 coupler.

Figure 4 shows output in decibels sound pressure level (dB SPL), using the Aweighting scale for each coupler as a function of frequency. At frequencies between 80 and $8000 \mathrm{~Hz}$, the two coupler measurements were similar to within $\pm 2 \mathrm{dBA}$. This finding verified that this modified coupler, using the Frye HA-1 coupler and the Larson-Davis 700 dosimeter microphone would be appropriate in determining sound exposure levels created by the hearing aids under test.

Industrial Sound Measurements. Industrial sound level measurements were made at the Sulzer-Bingham manufacturing plant. An employee working in the "tools" section 


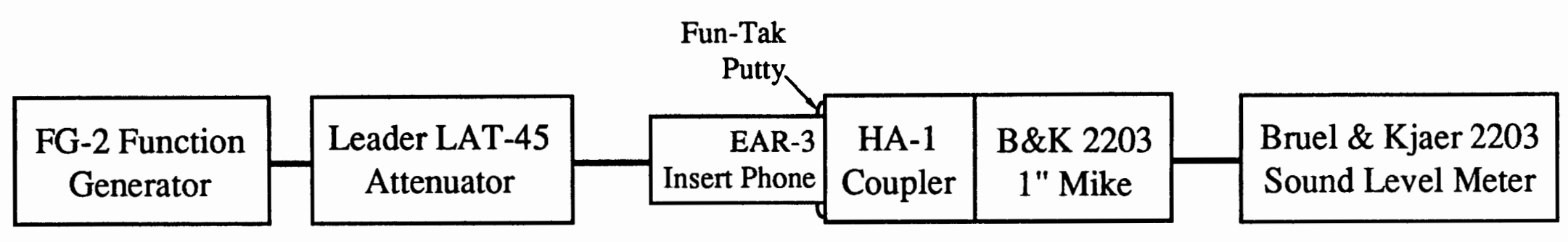

\begin{tabular}{|c|c|c|c|c|}
\hline $\begin{array}{c}\text { FG-2 Function } \\
\text { Generator }\end{array}$ & $\begin{array}{c}\text { Leader LAT-45 } \\
\text { Attenuator }\end{array}$ & $\begin{array}{r}\text { EAR-3 } \\
\text { Insert Phone }\end{array}$ & $\begin{array}{c}\text { Frye HA-1 } \\
\text { Coupler }\end{array}$ & $\begin{array}{c}\text { L-D 700 } \\
\text { Mike }\end{array}$
\end{tabular}

Figure 3. Instrumentation layout for comparison of coupler differences, including Bruel \& Kjaer sound level meter and Larson Davis 700 dosimeter. 


\section{Coupler Differences}

\section{Level, dBA}

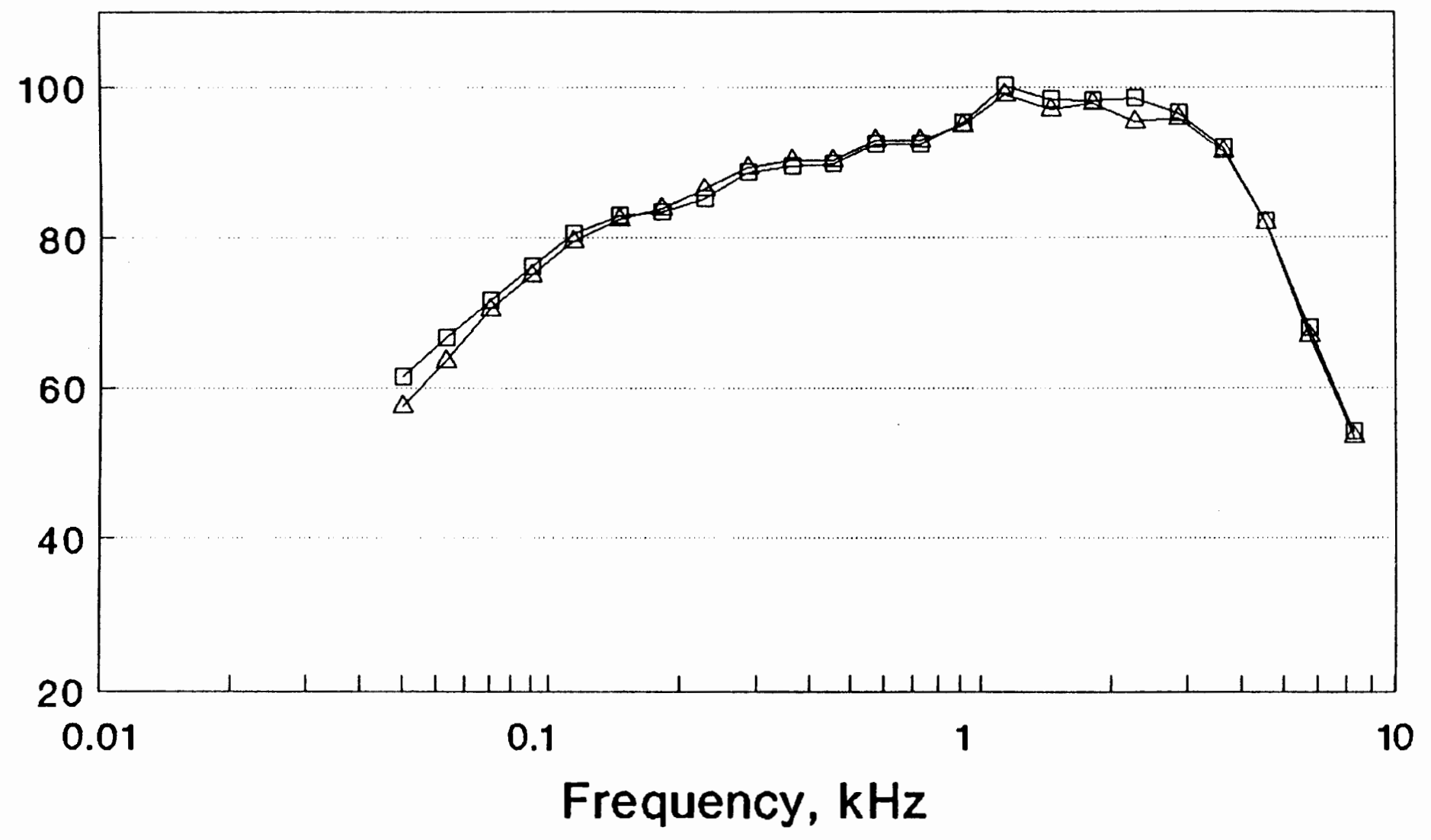

$\triangle$ - Sound Level Meter $\triangle$ Dosimeter

Figure 4. Coupler output level in decibels sound pressure level by frequency, $\mathrm{kHz}$. 
of light bay volunteered to wear the instrumentation during three separate eight hour shifts. The machine to which he was assigned during these days was a Heald G-4 Internal Diameter Grinder, Universal Model 273-A, which produced intensity levels of 80 to 100 dBA.

The majority of his work day was spent directly at the side of the grinding unit, but on occasion he attended to other tasks at a nearby station. When required to do so, he was working on another similar piece of equipment, known as a Cincinnati O-D Outside Diameter Grinder. This machine was noted as producing ambient noise levels reaching 90 to $100 \mathrm{dBA}$.

Prior to the daily recording and analysis of the noise at these work stations, both Larson-Davis Model 700 dosimeters were calibrated using the Bruel \& Kjaer pistonphone type 4220, as in Method One. Each dosimeter was programmed to run for exactly eight hours, beginning and ending at the same time. The microphone of one instrument was clipped to the shoulder piece which was securely pinned to the employee's shirt. This microphone measured the ambient noise levels in dBA. The microphone for the other dosimeter was inserted into the modified Frye HA-1 coupler (Figure 5). Three separate eight-hour shifts were analyzed, coupling individually the Starkey CE mild gain aid, the Bausch \& Lomb moderate gain aid, and the Widex A18+H high gain aid. All hearing aids were again set and taped to reference test position for the recording.

During all measurements, both dosimeters were placed in protective cases, and placed on the employee's belt, as was suggested by the manufacturer. Worn for the entire eight hour shift, both ambient and amplified noise levels were recorded and analyzed by 
Dosimeter mike

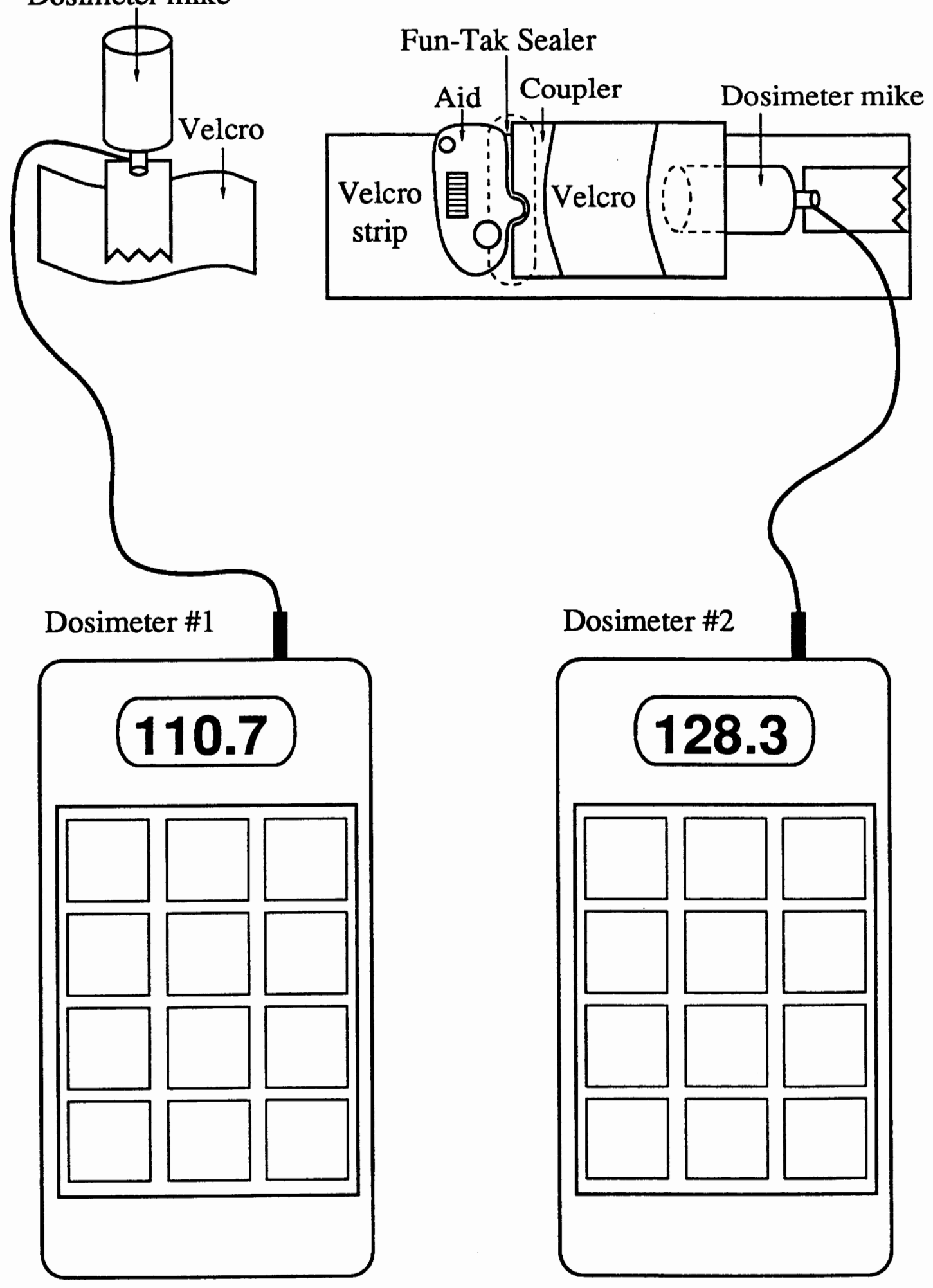

Figure 5. Example output levels by dosimeters when measuring ambient noise and when coupled to hearing aid. 
the dosimeters. Following each work shift, the instruments were collected by the researcher and taken back to the lab for analysis.

Non-Industrial "Everyday" Sound Level Measurements. In addition to exposure levels created by various amounts of gain provided by hearing aids in an industrial setting, this researcher made similar comparisons in non-industrial "everyday" listening situations. The purpose was to ascertain the intensity levels to which a hearing aid user would be exposed during daily activities. To make such measurements, this researcher spent three days wearing both of the Larson-Davis 700 dosimeters just as in the industrial portion of this study. As in the previous cases, calibration of the instruments was completed prior to each measurement. The instruments were again programmed to run for eight hours, beginning and ending at the same time. One microphone measured ambient levels, and the other was coupled to a hearing aid exactly as described in the industrial setting.

The non-industrial "everyday" dosimetry occurred over three days as the instruments were worn by the researcher going about her daily tasks. One Larson-Davis 700 dosimeter measured ambient noise levels, while the other measured amplified versions of the ambient noise with its microphone being coupled to a variety of individual hearing aids. Measurements on the first two days were made during household and entertainment activities. Amplification for both days was provided by the Bausch \& Lomb R6 in-the-ear hearing aid. The final set of data was gathered while spending the Christmas holiday with family and friends, and the Widex A18+H behind-the-ear hearing aid was utilized for the amplified levels. 


\section{CHAPTER IV}

\section{RESULTS}

In method one, tape recorded noise was utilized in conjunction with KEMAR and a Zwislocki coupler to measure the output of a variety of hearing aids. Two-hour tape recordings were made in both the cab of a locomotive and an industrial manufacturing plant.

Figure 6 shows data obtained with the recorded locomotive noise. The equivalent continuous noise level (Leq) (see Appendix A for an explanation of this term), integrated over one minute time intervals is plotted in $\mathrm{dBA}$ as a function of time. The lowest curve represents the noise levels in the unaided condition, while the upper curves represent the noise levels when amplified by each of three hearing aids providing different amounts of gain. The lowest curve shows that the ambient noise levels ranged from approximately 80 to $90 \mathrm{dBA}$, with most measured intensities near $85 \mathrm{dBA}$.

The second curve represents measured noise levels when amplified by the Bausch \& Lomb R6 mild-to-moderate gain in-the-ear hearing aid. This curve closely follows that of the unaided condition, representing output of a similar range of intensities, but averaging approximately 10 to $12 \mathrm{dBA}$ higher. The third curve, representing the output of the moderate gain Electone 800 behind-the-ear hearing aid, reveals output intensity levels ranging from 104 to $109 \mathrm{dBA}$, outputs which are approximately $20 \mathrm{dBA}$ above the 


\section{Cab of Locomotive}
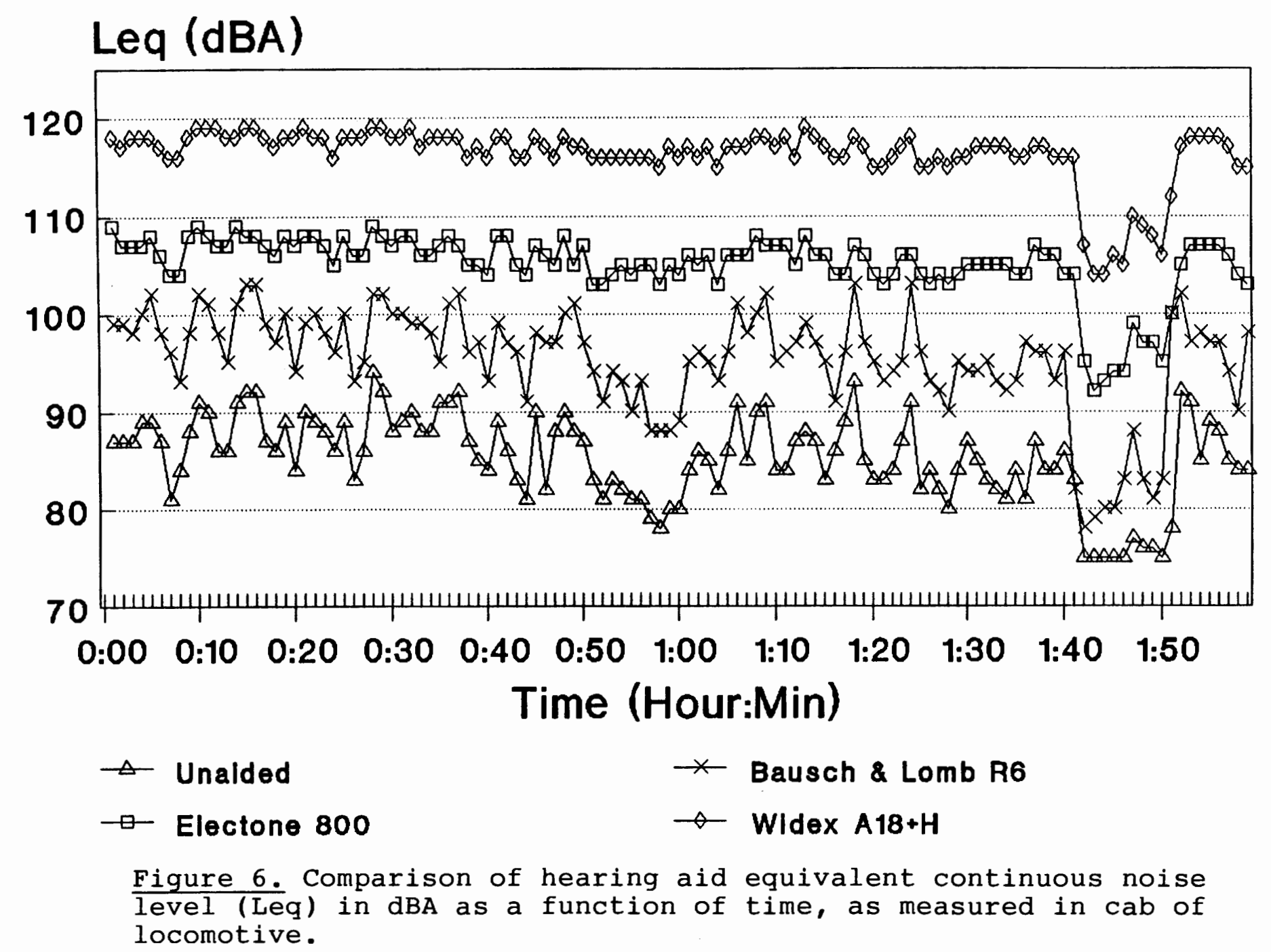
unaided curve. The fourth and highest curve represents noise levels produced by the high gain Widex A18+H behind-the-ear hearing aid. Intensity levels when amplified by this aid reached $117 \mathrm{dBA}$ and higher, increasing ambient levels by nearly $35 \mathrm{dBA}$.

While the output curve of the Bausch \& Lomb R6 is very similar in range to that of the unaided condition, the curves of both the Electone 800 and Widex A18 $+\mathrm{H}$ have smaller excursions. This suggests that the latter two hearing aids were in saturation due to the input levels. That is, the output levels of these hearing aids had reached their maxima

Based on the reference test gain measured in the Frye F20 hearing aid analyzer, one would expect to see the Bausch \& Lomb R6 output exceeding that of the Electone 800. This discrepancy was most likely due to the fact that when sealed into KEMAR's ear, the canal portion of the Bausch \& Lomb R6 was not tightly connected to the Zwislocki coupler. Specifically, there may have been a space between the hearing aid and the Zwislocki coupler.

Figure 7 shows the projected eight hour time-weighted averages (TWA's), in dBA using the OSHA method, as calculated by the Larson-Davis 820 Integrating Sound Level Meter. The unaided projected eight-hour TWA was $83.7 \mathrm{dBA}$, which is below the maximum permissible level of $90 \mathrm{dBA}$ as delineated by OSHA. The output of the mild gain Bausch \& Lomb aid caused the eight-hour projected TWA to increase to $95.4 \mathrm{dBA}$, which is $5.4 \mathrm{dBA}$ above OSHA's maximum permissible level of $90 \mathrm{dBA}$. The moderate gain Electone 800 increased this TWA to $105.4 \mathrm{dBA}, 15.4 \mathrm{dBA}$ above damage risk, and the high gain Widex aid amplified the noise to an eight-hour TWA of $116.6 \mathrm{dBA}$, an 


\section{Cab of Locomotive}

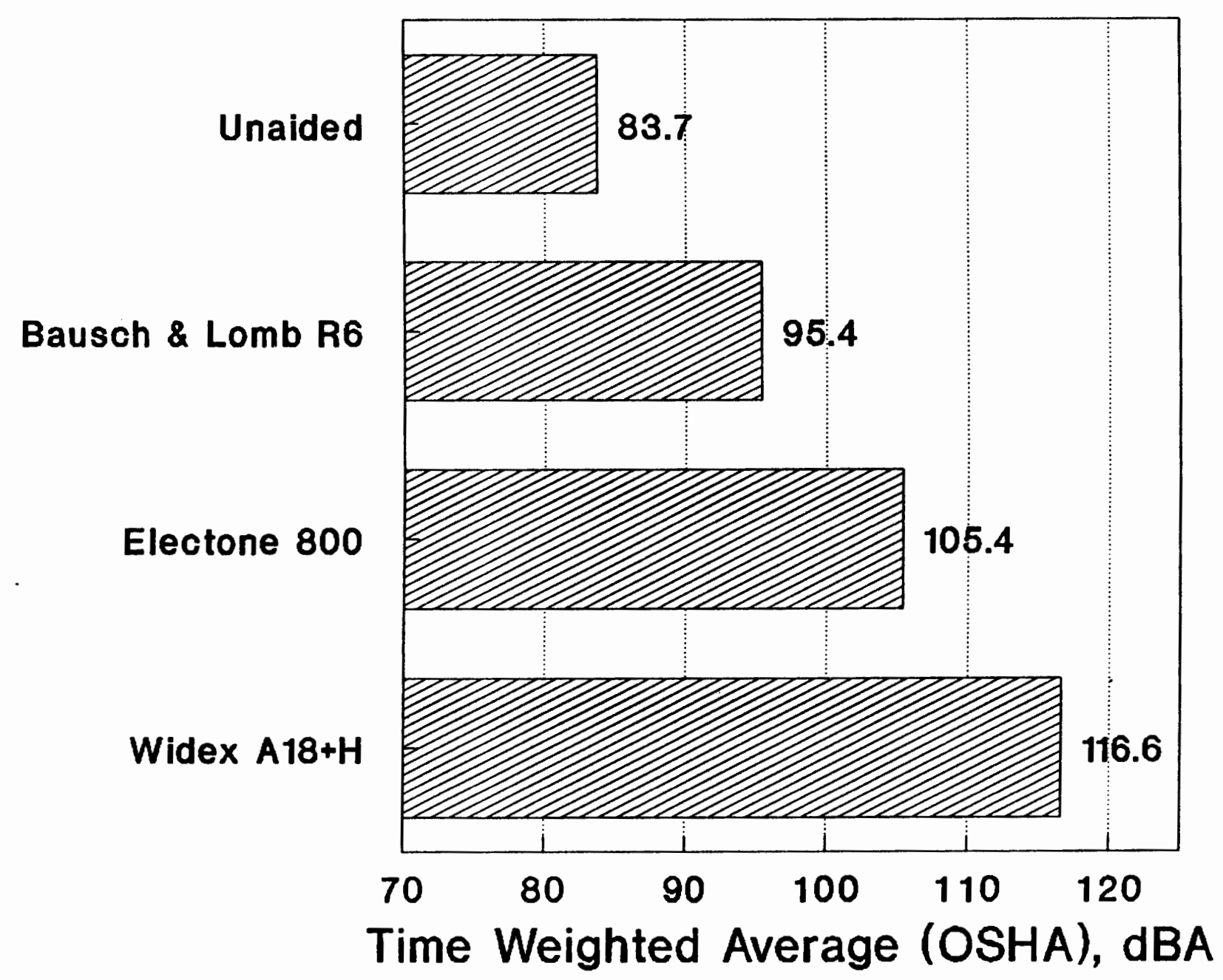

Figure 7. Projected eight hour time-weighted averages (TWA's) in dBA, calculated by integrating sound level meter, using locomotive noise recordings. 
exceedance of the legal limit by $26.6 \mathrm{dBA}$. Thus, when the noise was amplified by one of several hearing aids, the projected eight-hour TWA's exceeded the $90 \mathrm{dBA}$ level.

Figure 8 illustrates the equivalent continuous noise level (Leq) in dBA as a function of time for noise recorded at the T-5 Turret Lathe at the Sulzer-Bingham manufacturing plant. Intensity levels were measured and integrated over one-minute intervals for a two-hour period. The lower curve represents the unaided condition, which shows noise levels ranging from 80 to $88 \mathrm{dBA}$. The second curve represents output intensities of the Starkey CE mild gain hearing aid. The levels ranged from approximately 85 to $95 \mathrm{dBA}$, an increase of 5 to 10 decibels over the unaided condition. The third curve represents output levels of the Electone 800 hearing aid. Intensities covered a range similar to those of the two lower curves, but reveal an overall increase of 15 to $20 \mathrm{dBA}$ over the unaided condition. The uppermost curve shows output levels of the high gain Widex $\mathrm{A} 18+\mathrm{H}$ aid. The range of this hearing aid extended from 103 to $118 \mathrm{dBA}$, an increase of 30 to $35 \mathrm{dBA}$ over the unaided condition. Excursions on the aided curves are similar to those of the unaided condition, suggesting that the aids had not reached their saturation points during this set of measurements. This was most likely because the ambient noise levels were not of a magnitude which would cause saturation or peak clipping to occur.

Figure 9 gives the projected eight-hour OSHA TWA's in DBA for the unaided and aided conditions, based on the intensities in the two-hour Turret Lathe recording. The unaided, or ambient projected eight-hour TWA was determined to be $79.2 \mathrm{dBA}$. The amplification provided by the mild gain Starkey CE hearing aid produced a projected 


\section{Manufacturing Plant}

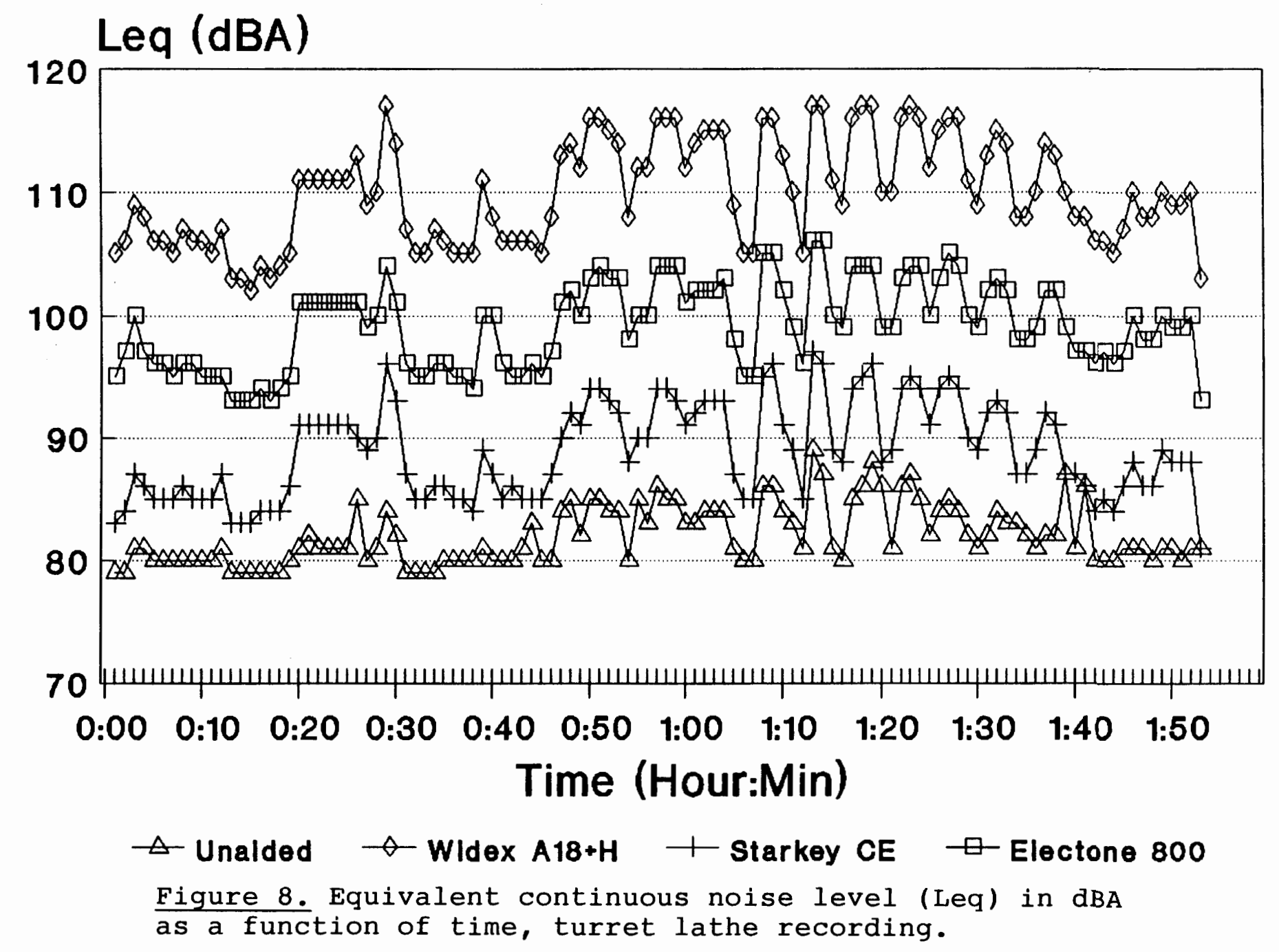




\section{Manufacturing Plant}

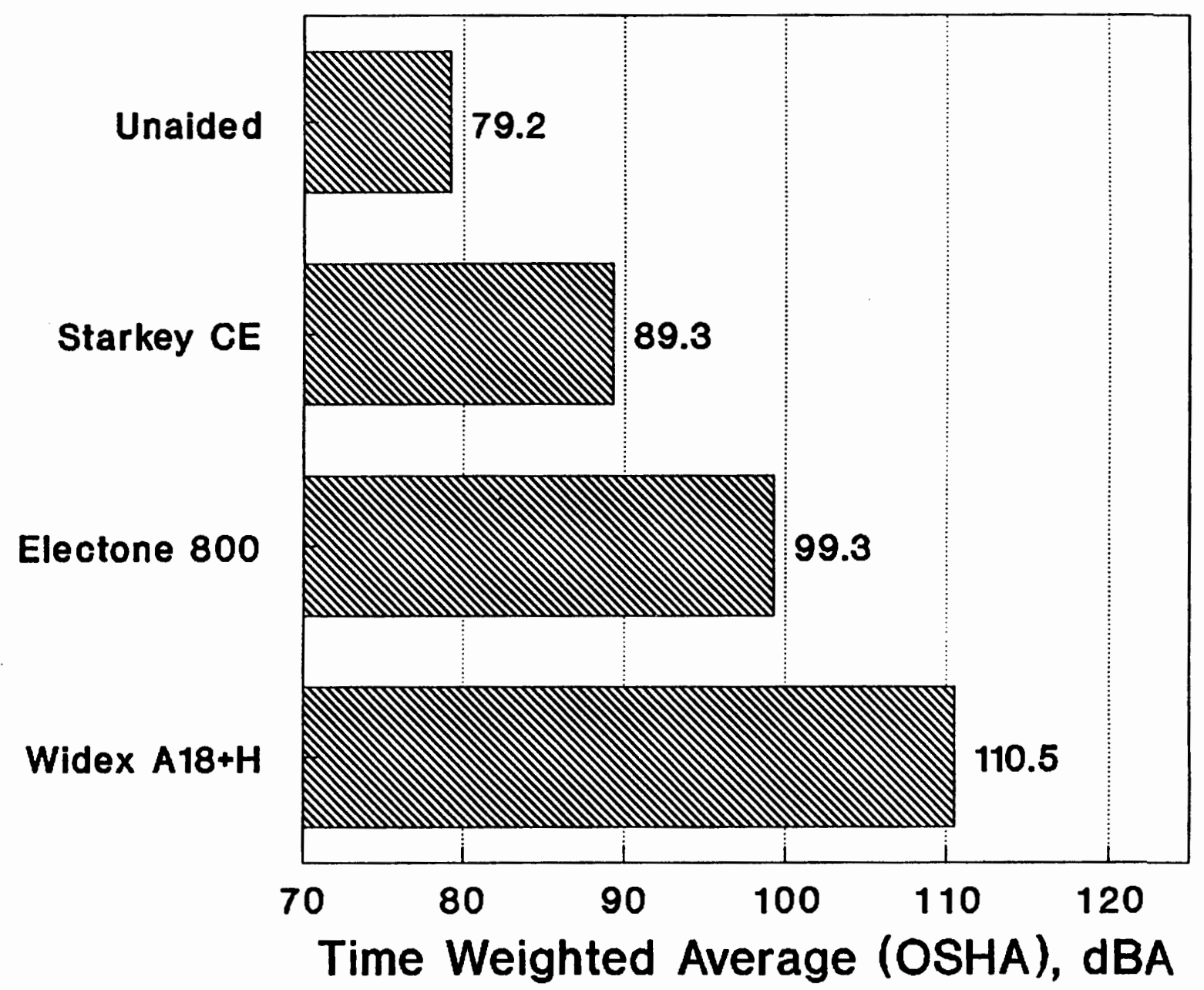

Figure 9. Projected eight hour time-weighted averages (TWAs) in dBA, calculated by integrating sound level meter, turret lathe recording. 
eight-hour TWA of $89.3 \mathrm{dBA}$. The moderate gain Electone 800 caused this TWA to increase to a level of $99.3 \mathrm{dBA}$, and the high gain Widex A18+H amplification lead to a projected eight-hour TWA of $110.5 \mathrm{dBA}$.

To summarize the aforementioned findings, all hearing aids except the Starkey CE amplified the ambient industrial TWA to levels exceeding the OSHA TWA maximum of $90 \mathrm{dBA}$.

The second set of noise measurements involved three days of on-site dosimeter analysis of industrial noise under both the unaided and aided conditions as recorded over an eight-hour period. On the first day, the mild gain Starkey CE in-the-ear hearing aid was coupled to one dosimeter. Figure 10 shows the equivalent continuous noise level (Leq) in $\mathrm{dBA}$ as a function of time. Data points represent sound levels integrated over four-minute periods. The lower curve represents the unaided condition, which on this day ranged from approximately 75 to $88 \mathrm{dBA}$. The upper curve represents output levels of the Starkey CE hearing aid. These intensity levels ranged from approximately 88 to 95 $\mathrm{dBA}$, suggesting an increase in exposure of about $10 \mathrm{dBA}$. The excursions of the curve in the aided condition were much narrower than those in the unaided condition, suggesting that at higher intensity levels, this hearing aid was peak clipping, and had been driven to the point of saturation.

The second day, the Bausch \& Lomb R6 in-the-ear hearing aid was coupled to the dosimeter to provide the aided conditions. Figure 11 illustrates the Leq in dBA as a function of time. Again, data points were plotted at four-minute intervals over the eighthour work shift. The unaided results on the lower curve reveal intensities ranging 


\section{Manufacturing Plant}

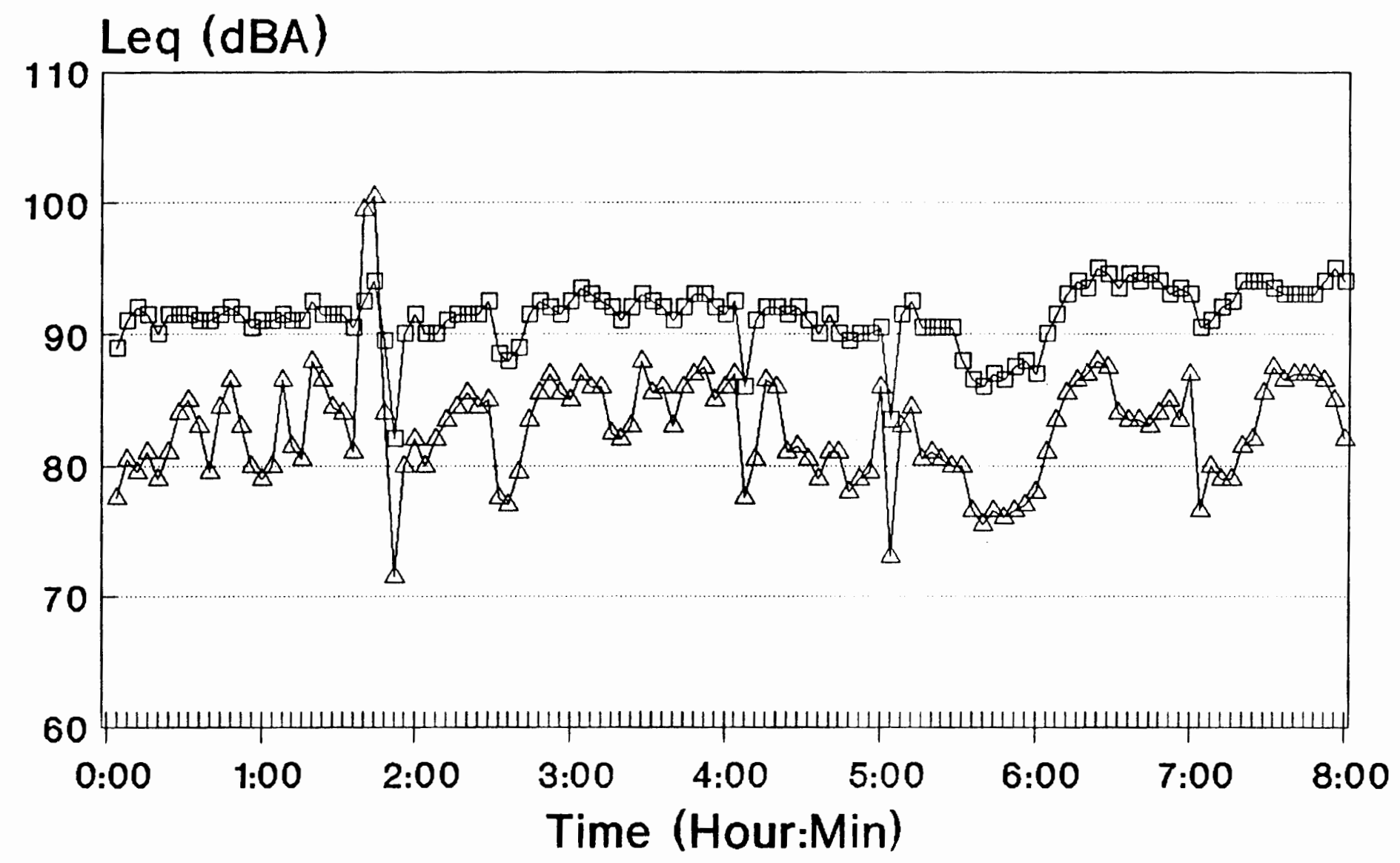

๑- Starkey CE $\triangle$ Unaided

Figure 10. Equivalent continuous noise level (Leg) in dBA as a function of time, manufacturing plant setting, starkey CE hearing aid. 


\section{Manufacturing Plant}

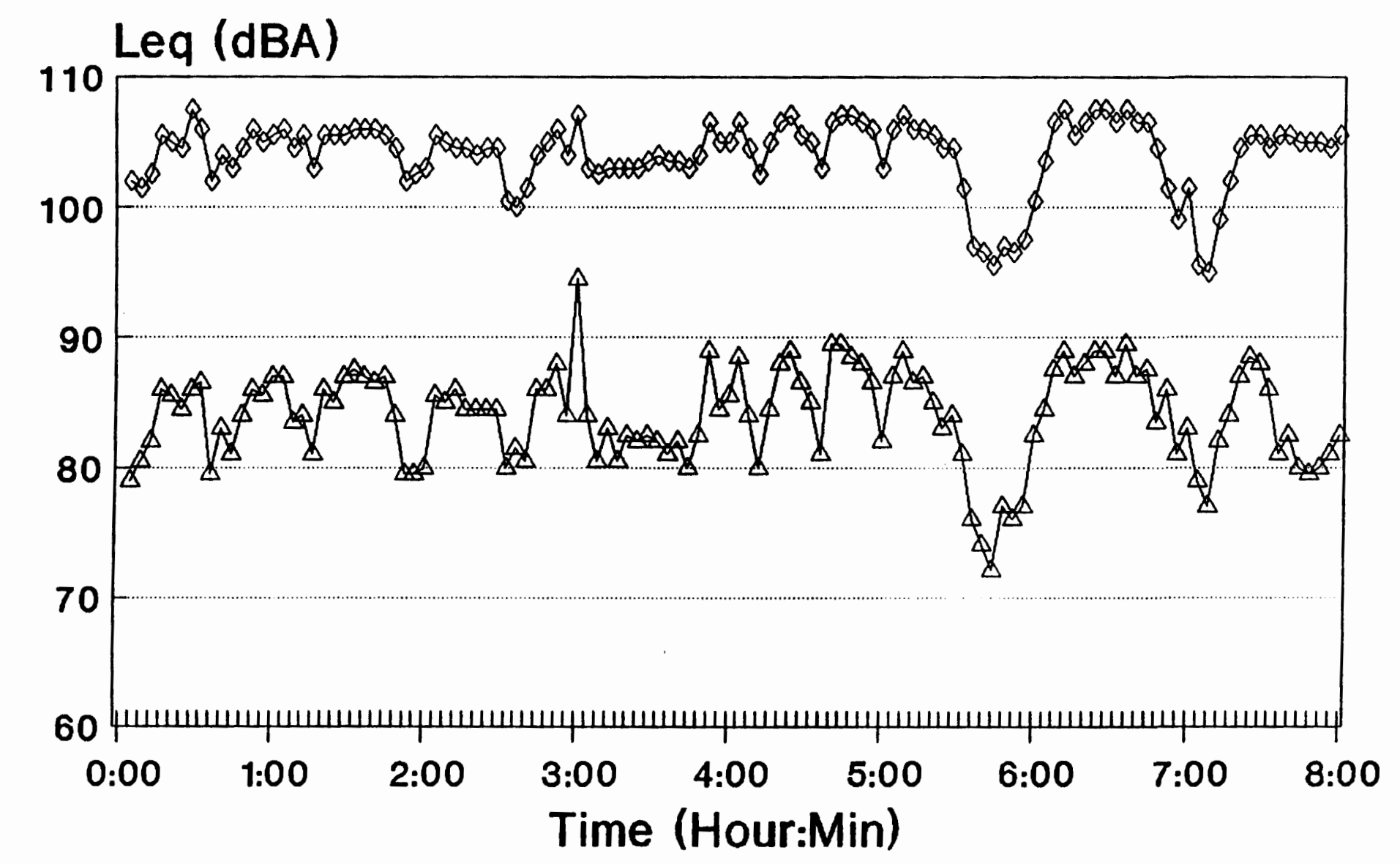

\section{$\triangle$ Unaided $\rightarrow$ Bausch \& Lomb R6}

Figure 11. Equivalent continuous noise level (Leq) in dBA as a function of time, manufacturing plant setting, Bausch \& Lomb R6 hearing aid. 
primarily from 80 to $90 \mathrm{dBA}$. The upper curve, representative of the aided output levels, contains intensities ranging from approximately 97 to $109 \mathrm{dBA}$, an increase of approximately $20 \mathrm{~dB}$ over the unaided condition. Again it was noted that while the curve for the aided condition followed that of the unaided curve, the reduced range between data points suggested that the hearing aid was at times being driven into saturation by the ambient noise input.

The third and final day, the high gain Widex $\mathrm{A} 18+\mathrm{H}$ behind-the-ear hearing aid was employed in the aided condition. Data for this condition are shown in Figure 12. The ambient noise levels remained in the 80 to $90 \mathrm{dBA}$ range. However, the Widex aid, even though set to reference test position, was instantly driven to its saturation level and remained there for the majority of the day. Aided Leq ranged from 110 to $118 \mathrm{dBA}$.

The OSHA eight hour time-weighted averages in $\mathrm{dBA}$ as recorded by the dosimeters are shown in Figure 13. The results from the first day, using the mild gain Starkey $\mathrm{CE}$, revealed an unaided TWA of $83.1 \mathrm{dBA}$, and an aided TWA of $91.8 \mathrm{dBA}$, an increase of $8.7 \mathrm{dBA}$. Results when coupled to the moderate gain Bausch \& Lomb R6 hearing aid revealed an unamplified eight-hour TWA of $84.1 \mathrm{dBA}$, and an aided TWA of 104.6 dBA, an amplification-induced increase of $20.5 \mathrm{dBA}$. When using the high gain Widex aid, the unaided eight-hour TWA of $82.6 \mathrm{dBA}$ was raised to an average of 116.4 $\mathrm{dBA}$, an increase of $33.8 \mathrm{dBA}$.

In each case, the ambient noise resulted in an OSHA time-weighted average below the OSHA maximum of $90 \mathrm{dBA}$. However, all three aids, whether providing mild, moderate or high gain when set to reference test position, amplified the ambient industrial 


\section{Manufacturing Plant}

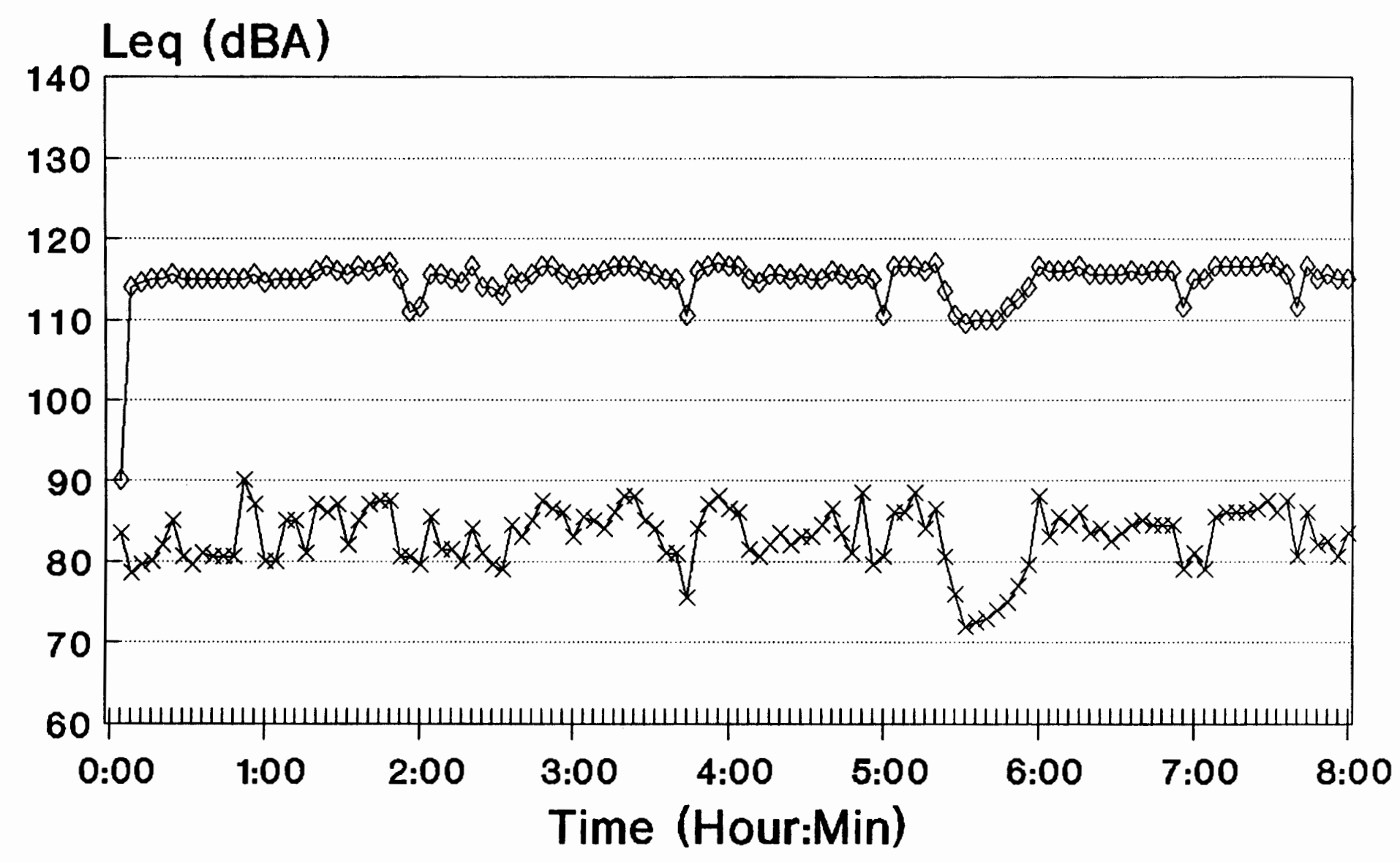

$\rightarrow$ Unaided $\rightarrow$ Widex $\mathrm{A} 18+\mathrm{H}$

Figure 12. Equivalent continuous noise level (Leq) in dBA as a function

of time, manufacturing plant setting, Widex $A 18+H$ hearing aid. 


\section{Manufacturing Plant}

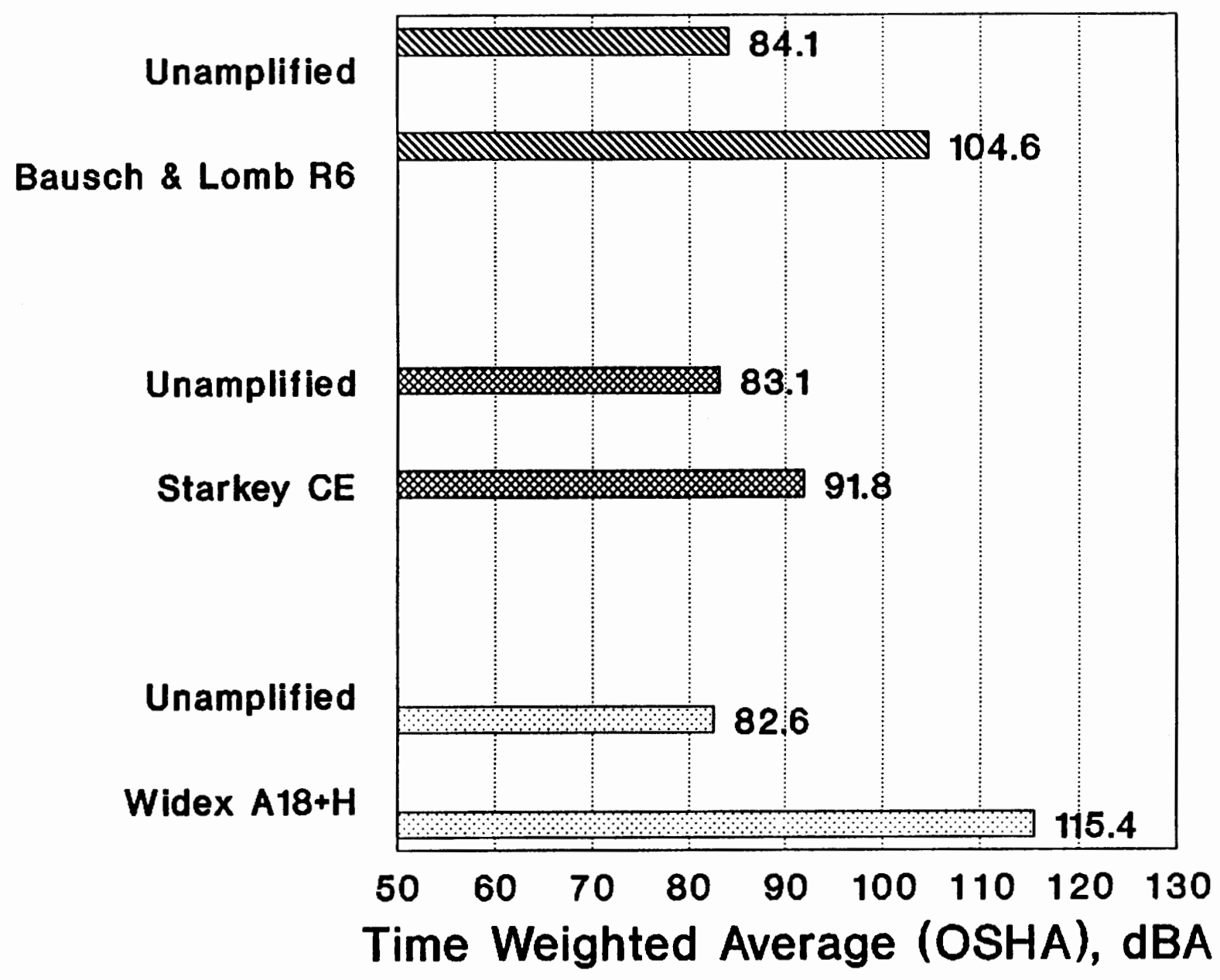

Figure 13. Eight hour time-weighted averages (TWAs) in dBA as calculated by dosimeters coupled with hearing aids, manufacturing plant setting. 
noise levels to time-weighted averages exceeding those set forth by OSHA as being legally permissible.

Non-industrial ambient and aided noise level measurements were made by this researcher during daily, non-occupational activities. The Larson-Davis 700 dosimeters were worn in the same manner as in the industrial setting, with one microphone picking up and analyzing ambient noise levels, and the other being coupled to one hearing aid at a time, and analyzing the amplified version of these levels.

One the first day, activities included household chores, driving the car, shopping in a grocery store and an outdoor barbecue with friends. Aided output levels were provided by the Bausch \& Lomb R6 in-the-ear hearing aid. Figure 14 represents the equivalent continuous noise level (Leq) as a function of time for both unaided and aided conditions. Data points represent sound levels integrated over two-minute periods for a total of eight hours. The lower curve illustrated unaided noise fluctuations ranging from approximately 55 to $68 \mathrm{dBA}$, centering about the 65 to $70 \mathrm{dBA}$ level. The higher intensities noted one to one-and-a-half hours into the recording represent driving in the car and shopping for groceries. The upper curve represents the aided condition, which follows very closely the curve in the unaided condition. Excursions range primarily from 80 to $95 \mathrm{dBA}$, an increase of approximately $15 \mathrm{dBA}$ over those in the lower curve.

At most points, the similarity in excursion size suggests that the hearing aid was not reaching saturation. However, when ambient levels reached near $80 \mathrm{dBA}$, the aided curve excursions became narrower in comparison. This evidence suggests that at this level and higher, the hearing aid was nearing its saturation level and peak clipping had 


\section{"Every-day" Listening Situation}

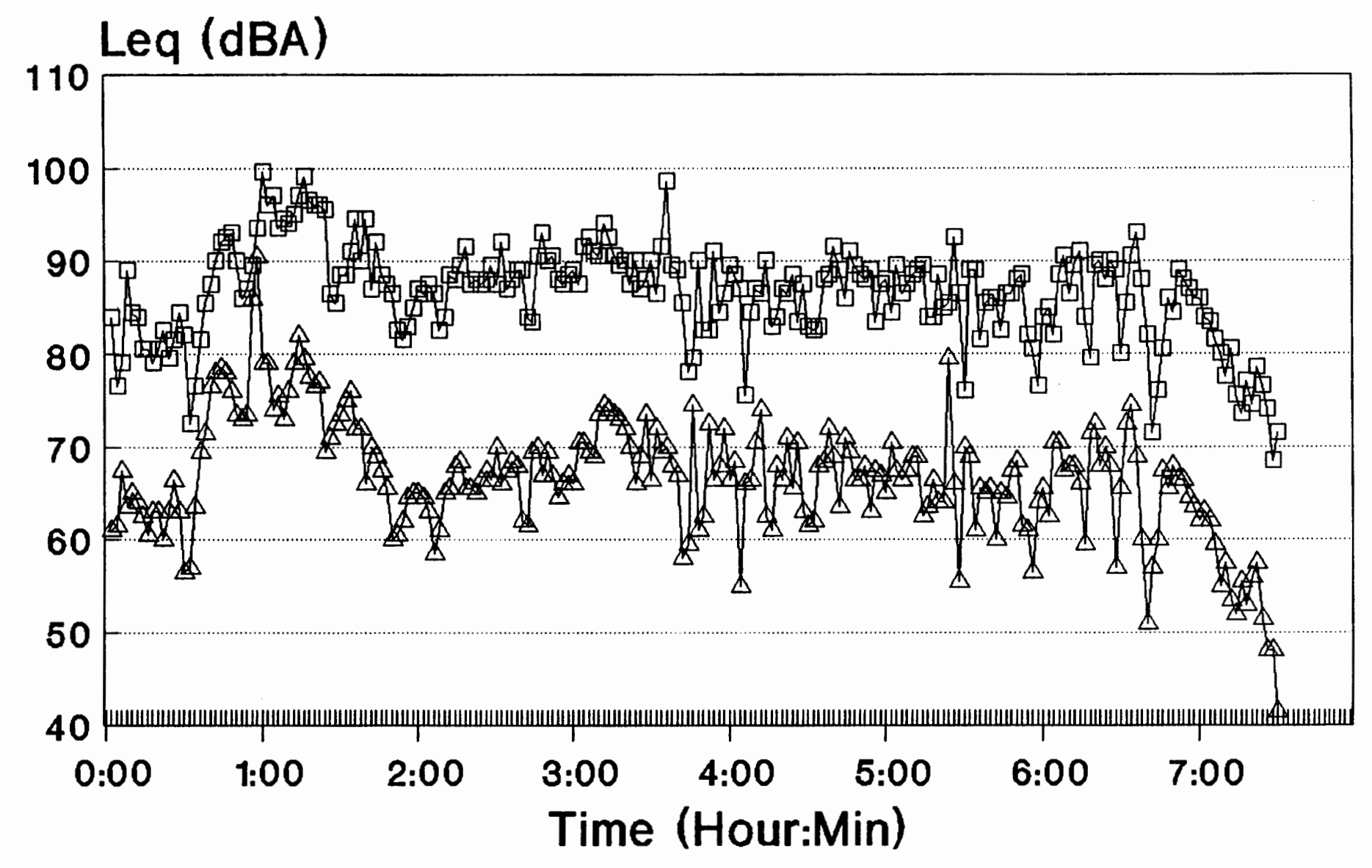

$\triangle$ Unaided $\square$ Bausch \& Lomb R6

Figure 14. Equivalent continuous noise level (Leq) in dBA as a function of time, non-industrial "every-day" setting, Bausch \& Lomb R6 hearing aid, home, driving, shopping, outdoor barbecue. 
begun.

The second "everyday" listening situation included sound measurements of similar noises in the home environment and those in a restaurant and nightclub setting, using the Bausch \& Lomb R6 hearing aid. Figure 15 shows Leq in dBA as a function of time, integrated in four-minute intervals over the eight hours. Again, the lower unaided curve shows ambient noise level fluctuations of 60 to $80 \mathrm{dBA}$ while at home. The ambient levels at the restaurant and lounge where music was playing were elevated to intensities of $80 \mathrm{dBA}$ and above. The aided curve generally follows that of the unaided condition at ambient intensity levels of $75 \mathrm{dBA}$ or less. However, when ambient input levels reached $80 \mathrm{dBA}$ or greater, the aided output narrowed significantly, suggesting peak-clipping and saturation of the hearing aid. Overall increase in $\mathrm{dBA}$ level caused by this moderate gain hearing aid's amplification appeared to be approximately $20 \mathrm{dBA}$, raising intensity output to levels of 100 to $105 \mathrm{dBA}$.

The third and final non-occupational measurements were made by coupling the high gain Widex $\mathrm{A} 18+\mathrm{H}$ hearing aid to one dosimeter, and recording noise levels on Christmas day while spending time with friends and family. Figure 16 shows unaided and aided Leq intensity levels in $\mathrm{dBA}$ as a function of time. The lower curve illustrates that unaided noise levels ranged from approximately 62 to $75 \mathrm{dBA}$. The nearly identical excursions and widths thereof noted in the upper curve suggest that this hearing aid output was, for the most part, not fully reaching its saturation level. To clarify, the nearly one-to-one $\mathrm{dBA}$ fluctuation change noted in the aided versus the unaided curve suggest that nearly all ambient noises and correlated intensities were equally amplified by the 


\section{"Every-day" Listening Situation}

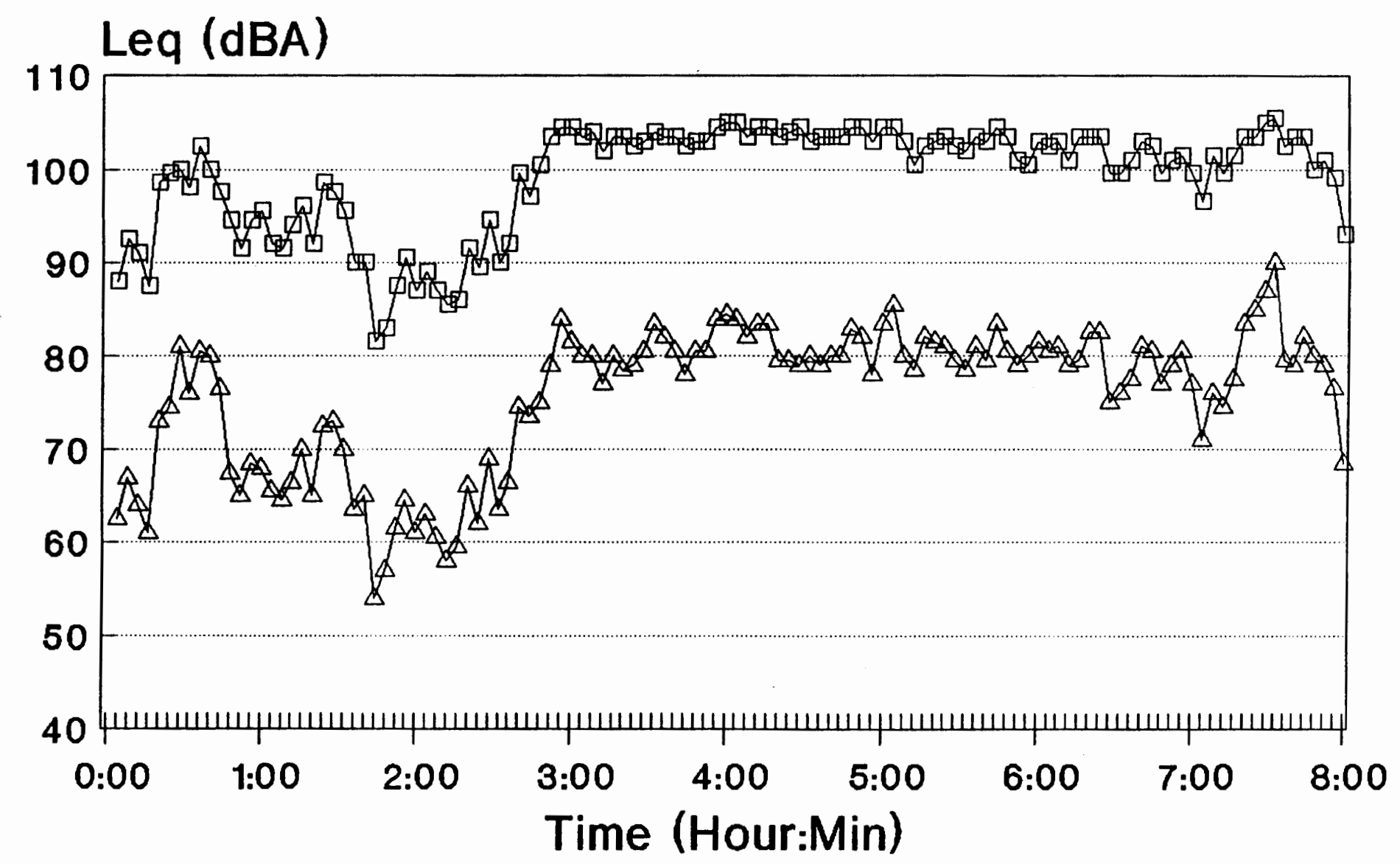

\section{$\triangle$ Unaided $\quad$ Bausch \& Lomb R6}

Figure 15. Equivalent continuous noise level (Leq) in dBA as a function of time, non-industrial "every-day" setting, Bausch \& Lomb R6 hearing aid, home, restaurant, nightclub. 


\section{"Every-day" Listening Situation}

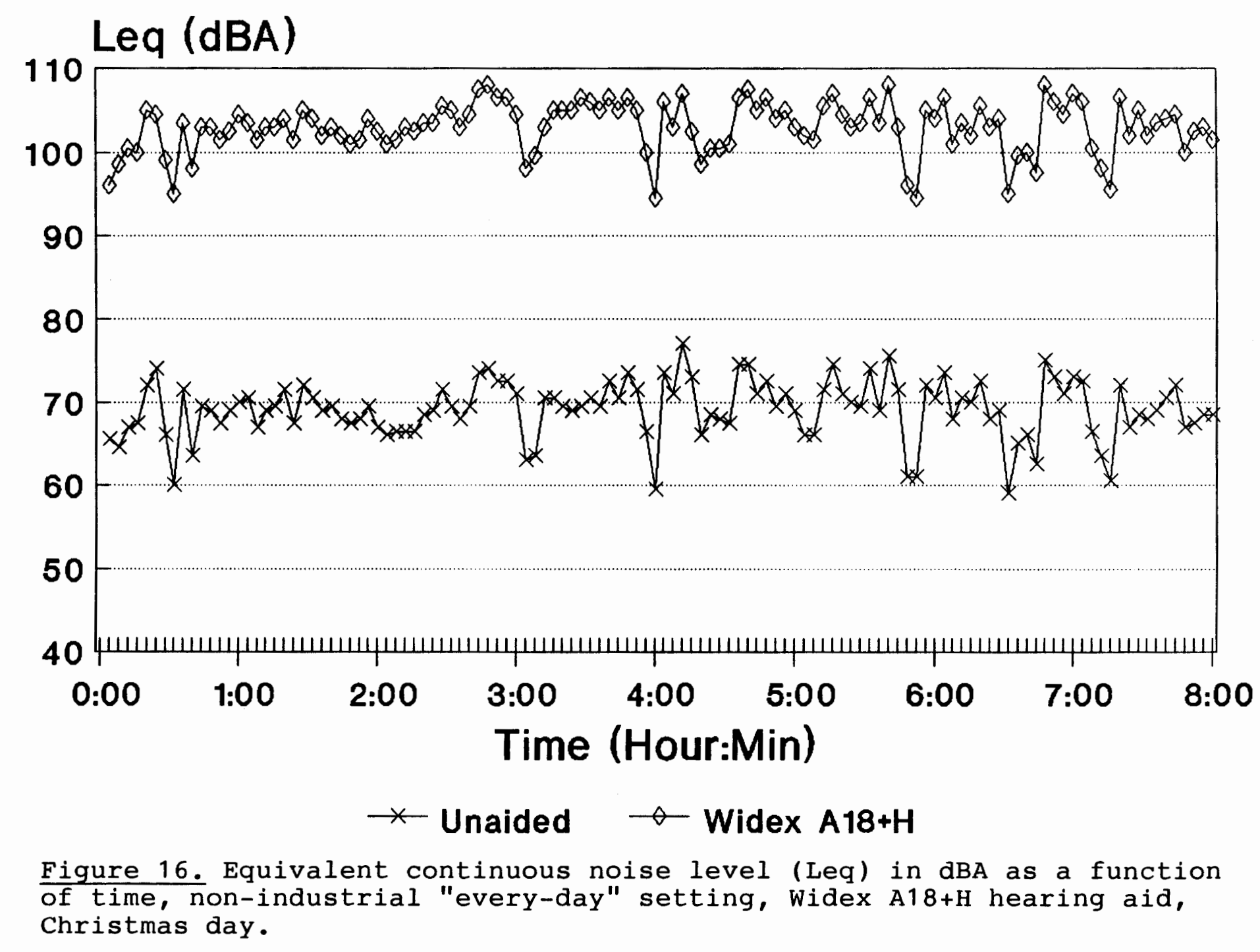


Widex aid. Most notably, ambient levels of a mere 68 to $70 \mathrm{dBA}$ were increased via amplification to nearly $105 \mathrm{dBA}$.

Figure 17 presents OSHA eight-hour time weighted averages in dBA for each of the non-industrial settings analyzed. The top two bars represent the unaided and aided conditions when recorded at home and at the barbeque. Ambient intensity levels resulted in a TWA of $61.3 \mathrm{dBA}$, while aided output of the Bausch \& Lomb R6 aid resulted in a TWA of $88.0 \mathrm{dBA}$, an increase of $26.7 \mathrm{dBA}$. When TWA's were compared in the restaurant/nightclub setting, a similar increase was noted. The middle two bars reveal an ambient TWA of $75.7 \mathrm{dBA}$, and that the Bausch \& Lomb's moderate gain amplification produced a TWA of $101.1 \mathrm{dBA}$, an increase of $25.4 \mathrm{dBA}$ over the unaided condition. When the high gain Widex $\mathrm{A} 18+\mathrm{H}$ hearing aid was employed, the most dramatic difference in TWA can be seen. An OSHA eight-hour TWA of only $56.6 \mathrm{dBA}$ in the unaided condition was increased to $103.8 \mathrm{dBA}$ in the aided condition.

In summary, Figure 16 reveals that in non-industrial, "everyday" listening situations, time-weighted averages are reasonably below damage risk intensities. However, amplification by hearing aids can result in the ambient noises being increased to intensity levels which can near, or even exceed, damage risk criteria as delineated by OSHA. 


\section{Every-day Listening Situations}

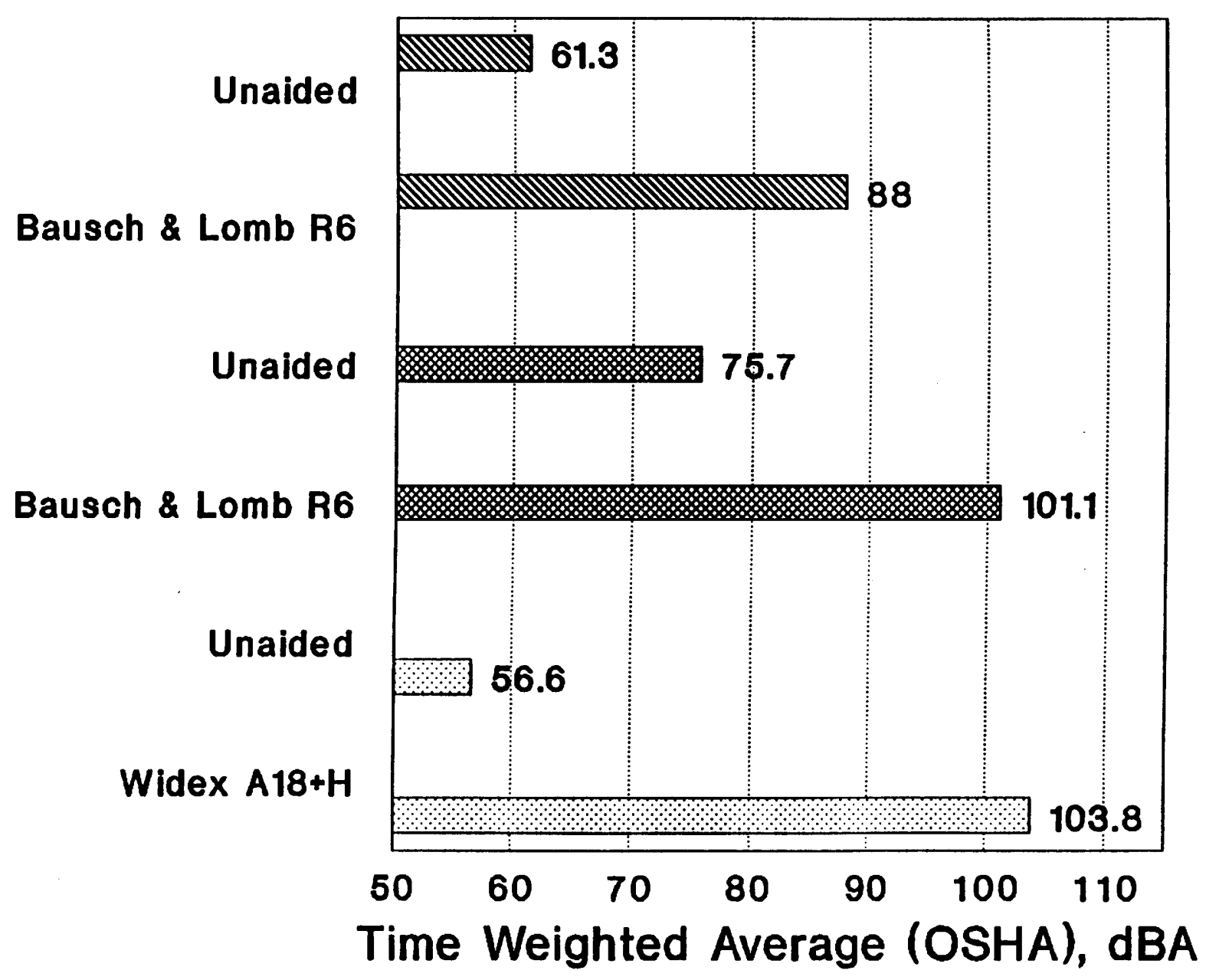

Figure 17. Eight hour time-weighted averages (TWAs) in dBA as calculated 


\section{CHAPTER V}

\section{DISCUSSION}

This study examined the noise exposure levels produced by hearing aids having mild, moderate and high gain. Measurements were made with dosimeters and a variety of hearing aids in both industrial and non-industrial settings. All comparisons were made in environments in which the ambient (unamplified) noise levels were less than $85 \mathrm{dBA}$. Occupational noise data were gathered using digital recordings from a locomotive and a manufacturing plant, as well as by making direct measurements of the noise at the manufacturing plant. Both sets of measurements revealed that the exposure levels created due to amplification by the hearing aids consistently exceeded the permissible OSHA maximum of $90 \mathrm{dBA}$ TWA. This was true not only in the case of moderate and high gain aids, but also of the mild gain aids. When using the most powerful aid, time-weighted averages were increased to a level of $116.6 \mathrm{dBA}$.

The data provided by measurements made in the non-industrial settings revealed similar results. Although ambient intensity levels were as low as $60 \mathrm{dBA}$, even a moderate amount of gain resulted in aided time-weighted average exposures of $88 \mathrm{dBA}$. The same hearing aid, when used in ambient levels of just below $80 \mathrm{dBA}$, amplified the noise to a time-weighted average of $101.1 \mathrm{dBA}$. The high gain aid increased such intensities to levels of up to $103.8 \mathrm{dBA}$. 
Clearly, then, even mild gain hearing aids may provide enough amplification that moderate levels of ambient noise can be increased to levels exceeding the OSHA maximum of $90 \mathrm{dBA}$. There are, nevertheless, many people who rely on hearing aids at work and at home. If OSHA regulations were to be strictly interpreted, it would appear that any employer who allows any of their workers to wear a hearing aid in an environment in which noise levels near or exceed such limits could possibly be in violation of these regulations.

This notion, however, is tempered by previous research (Humes \& Bess, 1981; Macrae, 1968, 1991; Macrae \& Ferrant, 1965), which focused on temporary and permanent threshold shifts in the hearing aid wearer. It has been suggested that for a given exposure, the amount of threshold shift is less in an ear with pre-existing loss than in one without such a loss. Therefore, exposure levels higher than $90 \mathrm{dBA}$ may not necessarily be as detrimental to the hearing of a previously-impaired individual as to one with normal hearing acuity.

All of the hearing aids used in these measurements were set to reference test position, as an estimate of the setting normally used by the hearing aid wearer. Even this volume control setting resulted in peak clipping in some hearing aids. Individuals often set the volume on their hearing aids to an even higher level, resulting in even greater outputs than those recorded in this study. Therefore, the exposure levels shown in this writing could be realistic in some cases.

An additional point to consider is the spectral content of the noise in question. If the pre-existing loss is primarily in the higher frequencies, as is often the case, and the low 
frequency thresholds are normal, low frequency input of high intensity may result in a shift of these thresholds. To further ascertain the actuality of such a hypothesis, however, a study of temporary threshold shift in hearing aid users is warranted.

The results of this study are not meant to infer that employers should feel negatively about having a hearing aid wearer in their employ. On the contrary, this data provides information as to the potential noise levels to which the hearing impaired may be exposed. The next step, then, is to address methods of reducing the exposure levels caused by the hearing aid's amplification.

For the hearing aid wearer in both industrial and non-industrial settings, the audiologist may need to educate them regarding methods of limiting their exposure by reducing the maximum power output and gain of the aid, as well as limiting the time that the aid is worn in that environment. Such counseling should be an integral part of the initial fitting of the aid, so that the patient fully understands the volume control settings, the potential output of the aid, and making educated decisions regarding when, how long, and at what level to wear the instrument.

For those who spend a good deal of their work or non-occupational time in loud environments, hearing aids designed with an automatic gain control (AGC) circuit could be utilized. Though the reduction in output is not instantaneous, and would not prevent high exposure levels due to impulse noise, the overall output levels when averaged over eight hours could be limited with this type of circuit.

Finally, if necessary, the hearing aid user could be counseled to turn the volume down, or completely off during times of very high noise exposure. He or she can utilize 
the hearing aid when it is necessary to assess machinery malfunction or converse with coworkers, but reduce their exposure as much as possible throughout their workday. In addition, employers monitoring their employees' auditory status can keep the hearing aid wearer informed as to any noted changes, and further counseling and training could be implemented when necessary.

The results of this study suggested that the hearing aid users in industrial and nonindustrial settings may very well be exposed to intensity levels which exceed OSHA maximums, even when ambient levels do not. The extent to which these are exceeded are based on the gain and output of the individual hearing aid in use. The criteria set forth by OSHA regarding the sound levels permitted in industry may not be appropriate in the hearing aid user's case, based on previous research regarding pre-existing hearing loss. The use of controlled volume wheel and output settings, automatic gain control (AGC) hearing aids, and counseling of the hearing aid wearer can all aid in the reduction of the intensity levels to which this population may be exposed. In addition, more complete analysis of temporary threshold shift in the hearing aid wearer would be very beneficial in developing an appropriate OSHA protocol for hearing aid use in industry. 


\section{SELECTED BIBLIOGRAPHY}

Bellefleur, P. A., \& VanDyke, R. C. (1968). The effects of hearing aid amplification on children in a residential school for the deaf. Journal of Speech \& Hearing Research, 11, 343-347.

Berger, E. H., Royster, L. H., \& Thomas, W.G. (1978). Presumed noise-induced permanent threshold shift resulting from exposure to an A-weighted Leq of $89 \mathrm{~dB}$. Journal of theAcoustical Society of America, 64(1), 192-197.

Bohne, B. (1976). Safe level for noise exposure? Annals of Otology. Rhinology \& Laryngology, $\underline{85}, 711-725$.

Botsford, J. H. (1967). Prevalence of impaired hearing and sound levels at work. The Journal of the Acoustical Society of America, 45(1), 79-82.

Burns, W. (1973). Noise and Man (2nd ed.). London: John Murray.

Burns, W. \& Robinson, D. W. (1970). Hearing and Noise in Industry. London: Her Majesty's Stationery Office.

Dennis, J. M., \& Neely, J. G. (1991). Otoneurologic diseases and associated audiological profiles. In J. T. Jacobson \& J. L. Northern (Eds.), Diagnostic Audiology (pp. 83109). Austin: ProEd.

Earshen, J. J. (1986). Sound Measurement: Instrumentation and Noise Descriptors. In E. H. Berger, W. D. Ward, J. C. Morrill, \& L. H. Royster (Eds.), Noise \& Hearing Conservation Manual (4th ed.) (pp. 37-95). Akron: American Industrial Hygiene Association.

Fox, M. S. (1957). Occupational Hearing Loss. Laryngoscope, 67, 1011-1016.

Gelfand, S. A., Silman, S., \& Ross, L. (1987). Long-term effects of monaural, binaural and no amplification in subjects with bilateral hearing loss. Scandinavian Audiology, 16, 201-207.

Gulick, W. L., Gescheider, G. A., \& Frisina, R. D. (1989). Hearing: Physiological Acoustics, Neural Coding, and Psychoacoustics. New York: Oxford. 
Harford, E. R., \& Markle, D. M. (1955). The atypical effect of a hearing aid on one patient with congenital deafness. Laryngoscope, $\underline{65}, 970-972$.

Hawkins, D. B. (1982). Overamplification: A well-documented case report. Journal of Speech and Hearing Disorders, 47(4), 376-382.

Heffernan, H. P., \& Simons, M. R. (1979). Temporary increase in sensorineural hearing loss with hearing aid use. Annals of Otology, 88, 86-91.

Holmgren, L. (1939). Can the hearing be damaged by a hearing aid? Acta

Otolaryngologica, 28, 440-449.

Humes, L. E. (1978). Temporary threshold shift from hearing aid usage. Journal of the Acoustical Society of America, 63, S65.

Humes, L. E., \& Bess, F. H. (1981). Tutorial on the potential deterioration in hearing due to hearing aid usage. Journal of Speech \& Hearing Research, 24, 3-15.

Jerger, J. F., \& Lewis, N. (1975). Binaural hearing aids: Are they dangerous for children? Archives of Otolaryngology, 101, 480-483.

Kinney, C. E. (1953). Hearing impairments in children. Laryngoscope, 63, 220-226.

Kinney, C. E. (1961). The further destruction of partially deafened children's hearing by the use of powerful hearing aids. Annals of Otology, 70, 828-835.

Kirkwood, D. H. (1990). U.S. hearing aid sales summary. The Hearing Journal, 43(12), 713.

Lipscomb, D. M. (1988). Determination of noise exposure. In Lipscomb, D. M. (Ed.), Hearing Conservation: In Industry, Schools and the Military. (pp. 35-44). San Diego: College Hill Press.

Macrae, J. H. (1968). Temporary threshold shifts and recovery from TTS after use of powerful hearing aids. Journal of the Acoustical Society of America, 43(6), 14451446.

Macrae, J. H. (1968). Deterioration of the residual hearing of children with sensorineural deafness. Acta Otolaryngologica, 66, 33-39.

Macrae, J. H. (1991). Permanent threshold shift associated with overamplification by hearing aids. Journal of Speech \& Hearing Research, 34, 403-414. 
Macrae, J. H. (1993). Temporary threshold shift caused by hearing aid use. Journal of Speech \& Hearing Research, 36, 365-372.

Macrae, J. H., \& Ferrant, R. H. (1965). The effect of hearing aid use on the residual hearing of children with sensorineural deafness. Annals of Otology, Rhinology \& Laryngology, 74, 409-419.

Mahon, W. J. (1984). U.S. hearing aid sales summary. The Hearing Journal, 37(12), 7-12.

Mahon, W. J. (1985). U.S. hearing aid sales summary. The Hearing Journal, 38(12), 7-13.

Mahon, W. J. (1987). U.S. hearing aid sales summary. The Hearing Journal, 40(12), 7-11.

Mahon, W. J. (1988). U.S. hearing aid sales summary. The Hearing Journal, 41(12), 7-12.

Mahon, W. J. (1989). U.S. hearing aid sales summary. The Hearing Journal, 42(12), 7-13.

Markides, A. (1976). The effect of hearing aid use on the user's residual hearing Scandinavian Audiology, , 205-210

Melnick, W. (1985). Industrial Hearing Conservation. In J. Katz, W. L. Gabbay, D. S. Ungerlaider, \& L. Wilde (Eds.), Handbook of Clinical Audiology (3rd ed.) (pp. 721-741). Baltimore: Williams \& Wilkins.

Melnick, W. (1991). Human temporary threshold shift (TTS) and damage risk. Journal of the Acoustical Society of America, 90(1), 147-154.

Miller, M. H. (Ed.). (1985). Council for Accreditation in Occupational Hearing Conservation Manual (2nd ed.). Springfield: Associated Management Corporation.

Mills, J. H. (1973). Threshold shifts produced by exposure to noise in chinchillas with noise-induced hearing losses. Journal of Speech \& Hearing Research, 16, 700-708.

Naunton, R. F. (1957). The effect of hearing aid use on the user's residual hearing. Laryngoscope, 67, 569-576.

Newby, H. A., \& Popelka, G. R. (1985). Audiology (5th ed.). Englewood Cliffs: PrenticeHall.

Northern, J. L., \& English, G. M. (1991). Otologic evaluation. In J. T. Jacobsen \& J. L. Northern (Eds.), Diagnostic Audiology (pp. 67-81). Austin: Pro Ed. 
Reilly, K. M., Owens, E., Uken, D., McClatchie, A. C., \& Clarke, R. (1981). Progressive hearing loss in children: Hearing aids and other factors. Journal of Speech and Hearing Disorders, 46 , 328-334.

Rintelmann, W. F., \& Bess, F. H. (1977). High-level amplification and potential hearing loss in children. In F. H. Bess (Ed.), Childhood Deafness: Causation. Assessment and Management (pp. 267-293). New York: Grune \& Stratton.

Roberts, C. (1970). Can hearing aids damage hearing? Acta Otolaryngologica, $\underline{69}, 123-$ 125 .

Ross, M., \& Lerman, J. (1967). Hearing aid usage and its effect upon residual hearing: A review of the literature and an investigation. Archives of Otolaryngology, $\underline{86}, 57-$ 62.

Ross, M., \& Truex, E. H. Jr. (1965). Protecting residual hearing in hearing aid user (sic). Archives of Otolaryngology, $\underline{\text { 82, }}$ 615-617.

Sataloff, J. (1961). Pitfalls of routine hearing testing. Archives of Otolaryngology, 73 , 717-726.

Sataloff, J. (1966). Hearing Loss. Philadelphia: Lippincott.

Sataloff, J., Menduke, H., \& Hughes, A. (1962). Temporary threshold shift in normal and abnormal ears. Archives of Otolaryngology, $\underline{76}, 52-54$.

Saunders, J. C., Yale, E. C., \& Szymko, Y. M. (1991). The structural and functional consequences of acoustic injury in the cochlea and peripheral auditory system: A five year update. Journal of the Acoustical Society of America, 90(1), 136-146.

Silman, S., \& Silverman, C. A. (1991). Auditory Diagnosis: Principles and Applications. San Diego: Academic Press.

Skinner, M. W. (1988). Hearing Aid Evaluation. Englewood Cliffs: Prentice Hall.

Suter, A. H. (1986). Hearing conservation. In E. H. Berger, W. D. Ward, J. C. Morrill, \& L. H. Royster (Eds.), Noise and Hearing Conservation Manual (4th ed.) (pp. 118). Akron: American Industrial Hygiene Association.

Suter, A. H. (1988). The development of federal noise standards and damage risk criteria. In D. M. Lipscomb (Ed.), Hearing Conservation: In Industry, Schools and the Military. (pp. 45-66). San Diego: College Hill Press. 
Tempest, W. (1985). Noise and hearing. In W. Tempest (Ed.), The Noise Handbook (pp. 47-67). London: Academic Press.

Titche, L. L., Windrem, E. O., \& Starmer, W. T. (1977). Hearing aids and hearing deterioration. Annals of Otology, $\underline{86}, 357-361$.

U. S. Department of Commerce. (1992). Statistical Abstract of the U.S. (112th ed). Lanham: Bernan Press.

Ward, W. D. (1969). Effects of noise on hearing thresholds. In W. D. Ward \& J. E. Fricke (Eds.), Conference on Noise as a Public Health Hazard (pp. 40-48). Washington DC: American Speech and Hearing Association.

Ward, W. D. (1984). Noise-induced hearing loss. In D. M. Jones \& A. J. Chapman (Eds.), Noise and Society (pp. 77-109). Chichester: John Wiley \& Sons.

Ward, W. D. (1986). Anatomy \& Physiology of the ear: Normal and damaged hearing. In E. H. Berger, W. D. Ward, J. C. Morrill \& L. H. Royster (Eds.), Noise and Hearing Conservation Manual (4th ed.) (pp. 177-195). Akron: American Industrial Hygiene Association.

Wyle Research (1981). Community noise assessment manual: Acoustical survey of a community (Contract No. 68-01-4694). Washington, D.C.: U.S. Environmental Protection Agency.

Yates, J. T., Ramsey, J. D., \& Holland, J. W. (1976). Damage risk: An evaluation of the effects of exposure to $85 \mathrm{vs.} 90 \mathrm{dBA}$ of noise. Journal of Speech \& Hearing Research, 19, 216-224.

Yost, W. A., \& Nielsen, D. W. (1985). Fundamentals of Hearing: An Introduction (2nd ed.). Fort Worth: Holt, Rinehart \& Winston. 


\section{APPENDIX A \\ EQUTVALENT CONTINUOUS SOUND LEVEL (Leq)}

The equivalent continuous sound level, or Leq, is equal to the continuous sound level of fluctuating environmental noise, integrated over a specified period of time, which results in the same amount of energy as would a constant sound level integrated over the same amount of time. It is defined by the formula:

$$
\text { Leq }=10 \log \llbracket 1 / T \int_{0}^{T} 10^{L} / / 10 \mathrm{dt} \rrbracket
$$

"where $t$ is the time in seconds, $T$ is the observation time and $\mathrm{L}_{A}$ is the A-weighted instantaneous sound level" (Earshen, 1986). It is actually a sound level which is based on the mathematical average of the energy content of the noise, rather than the mathematical average of the sound level. Such values are determined by taking sound measurements over periods of 1,8 , or 24 hours, and computing this information using the above formula (Wyle Research, 1981). 